\title{
Comparison of the Cat Paradoxical Eye Reaction and the Rabbit Intestine Strip Method for Assay of the Epinephrine Content of Blood of Cat.
}

\author{
By \\ TADASHI SUGAWARA. \\ （菅原正） \\ (From the Physiological Laboratory of Prof. Y. Satake, \\ Tồlokiu Imperial University, Sendai.)
}

\section{Contents.}

I. Use of the paradoxical eye reaction in the cat for determination of the epinephrine content in blood or extract as well as for auto-assay of epinephrine output from the suprarenals.

II. Parallel determinations of the epinephrine output by the methods of the autoassay (by the cava-pocket-paradoxical eye reaction) and by the cava-pocketrabbit intestine strip method.

III. Parallel determinations of the epinephrine content of the suprarenal vein blood, taken outside of cat body, by the cat paradoxical eye method and the rabbit intestine segment method.

IV. Summary.

About ten years ago Stew art and $R$ ogoff related a striking finding concerning the amount of epinephrine liberated from the suprarenal glands, that quite different values were yielded according to the methods employed, viz. the auto-assay by means of the paradoxical eye reaction on releasing the upper clamp of the cava pocket, or the assay of the blood collected out of the cava pocket by means of the rabbit intestine segment method. At that time the epinephrine output determined by the latter method was only about half as much, on an average, as that determined by the former. ${ }^{1}$ These results became later an object of serious criticism by Cannon and Rapport.2)

1) G. N. Stew art and J. M. Rog off, J. Pharm. Exp. Ther., 1917 (-18), 10, 2 ff.

2) W. B. Cannon and D. Rapport, Am. J. Physiol., 1921, 58, 325. 
Since it appeared to us to be worth while to re-investigate this finding, and to analyse, if it be the case, the present investigations were started in the spring of 1923. At first the mere re-investigation of the experiments of Stew art and Rogoff was undertaken. The results of our re-investigation were quite different from those of the Cleveland physiologists, that is, the epinephrine output determined by the rabbit intestine strip method was not only never inferior to that estimated by the auto-assay (by eye reaction), but invariably more or less exceeded the latter. In order to know the cause of this unmistakable difference in the quantity of epinephrine output on the employment of the different methods, another set of experiments was then undertaken. That is, of one and the same blood sample from the cava pocket a portion was tested by means of the rabbit intestine strip method while the remaining was used for estimation by its intravenous injection into the second cat previously deprived of the superior cervical ganglion. Some of the cats used for the latter purpose were previously doubly splanchnectomized.

When the first set of experiments were nearly concluded, I noticed the data of the new experiments ${ }^{3)}$ undertaken by the Cleveland physiologists for comparison of both the methods in the paper on "The average epinephrine output in cats and dogs."

These new results, viz. the data on the cats $814,815,816,817$ and 821 , which were published in that paper, agreed quite closely with those obtained by the present writer. In none of these five cats was the output determined by the intestine segment method inferior to that by the autoassay. In reality the ratio of value obtained by the auto-pupil-assay to that by the rabbit segment was $1: 1.2-1: 1.9$. In the present investigation 32 parallel determinations were performed on 19 cats, and the ratio was found as $1: 1.2-1: 2.8$. The ratio $1: 2.8$ was found only in a single case ; in the others it did not exceed $1: 2.2$. One may be justified in saying, therefore, that the ratio of the values obtained by these two methods in both laboratories, Cleveland and Sendai, practically agree with each other, notwithstanding the small number of the experiments cited in their paper.

This close agreenent of the ratio affords another reason to believe that the rabbit intestine strip method practised in our Laboratory by no means essentially differs from that employed in the Cushing Laboratory, despite their (riticisms ${ }^{4}$ ) on the earlier communications from our Laboratory. In passing, it may be noted that the invalidity of their

3) G. N. Stew art and J. M. Rogoff, Am. J. Physiol., 1923, 66, $243 \mathrm{ff}$.

4) G. N. Stewart and J. M. Rogoff, Am. J. Physiol., 1924, 69, 605. 
criticisms was fully discussed on a previous occasion.5)

In comparing both the methods $S$ tewart and Rogoff took into account the two cases published in 1917, the results of which by no means harmonized with the new ones. By putting both the sets, old and new, together, they were able to obtain the average output as estimated by the auto-assay 0.00034 mgrms. per kilo per minute, and as estimated by the intestine segment 0.00036 . Though they pronounced that no great weight should be attached to the close agreement, which is accidental, their conclusion was that the results of the 7 experiments indicate that there is no deficiency in the output determined by the intestine segment method. They laid no special stress, however, on the results of the new experiments on 5 cats, which indicate one and the same tendency without exception.

The second set of the present investigations, that is, the parallel estimation of the blood from one and the same sample from the cava pocket outside of that cat body by the paradoxical eye reaction in the second cat and by the rabbit intestine segment gave quite the same ratio as the first series of researches.

The parallel estimations, 37 in number, performed on 10 cats yielded an unexpected and surprising result. The ratio (eye reaction to rabbit segment) was indeed $1: 1.2-1: 2.7$ too. After all this fact must be taken to indicate that the suprarenal vein blood of cats possesses a somewhat definitely greater action upon the rabbit intestine segment than upon the cat pupil, the superior cervical ganglion to which was previously interfered with, the action of adrenaline hydrochloride being taken as the standard.

Illustration of the data will now follow the description of the method of the paradoxical pupil reaction of the cat, the splanchnic nerves of which were remained untouched or previously interfered with for determination of the epinephrine content of blood or extract.

I.

\section{Use of the Paradoxical Eye Reaction in the Cat for}

Determination of the Epineperine Content in

Blood or Extract as Well aS For AUto-

Assay of the Epinephrine OdTPut

From the SUPRarenals.\$

After the discovery of the action of adrenaline upon the denervated eye (viz. the sympathetic ganglion to which has been beforehand inter-

5) Tadashi Sugawara, Masa. Watanabé, Shidzuka Saito, Tohoku J. Exp. Med., 1926, 7, 3-26.

$\S$ The essential of this chapter was presented before the IV. Jap. Physiological Meeting at Mukden, 1925 (J. Biophysics, 1927, under press.). 
fered with), the paradoxical eye reaction has been applied by some experimentalists for assay of the epinephrine output from the suprarenals. It must be remembered, however, that adrenaline or epinephrine is by no means the sole agent capable of causing the paradoxical eye reaction. Some other factors, as severe asphyxia, ether, etc., can evoke it, even in the ani$\mathrm{mal}$ in which the epinephrine output wholly or largely interfered with.

By the paradoxical eye reaction, on the other hand, we are advantageously enriched in the kinds of biological methods for the assay of epinephrine content in bloods or extracts, though we have no previous reference of such utilization of this reaction. This method can also be employed in conjunction with making the cava pocket simultaneously for estimation of epinephrine ontput from the suprarenals, as Stewart and Rogoff employed it.

Since we have consequently somewhat systematically studied utilization of this reaction for the purposes stated in the heading of this chapter and have come to acknowledge some particulars worthy of remark, a full description of this method will in the first place be presented in the following pages.

For assay of the epinephrine content by the partially denervated (that is, the sympathetic ganglion alone was extirpated, and not the ciliary ganglion) pupil cats are used in our Laboratory exclusively, because of the ease with which the pupil width is measured, and of the relatively superficial situation of the cervical ganglion, in comparison with the dog.

The superior cervical ganglion was aseptically excised on one side under ether anaesthesia about one to three weeks prior to the principal experiment. In the very beginning of the present investigations the left ganglion or the right was removed at random, but soon after we confined ourselves to operating only on the left ganglion because of its somewhat superficial locality.

For the principal experiment urethane was given stomachically to the cat with the partially denervated eye in a dose such as $\mathbf{1 . 5}$ grms. per kilo of body weight. When vomiting set in, which was frequently, a small additional amount was required before a satisfactory degree of anaesthesia was achieved. The animal must be always so deeply anaesthetized, that the pinna reflex is totally or nearly completely abolished, otherwise the mechanical stimulation incident to various procedures attendant necessarily in carrying out the determination may also cause the paradoxical eye reaction and consequently totally vitiate the experimental data.

When anaesthesia was found to be complete-usually a matter of one 
half or one hour-, the cat was fixed on its back on the table-something like a box-, the upper copper plate of which was heated when wanted, by electric lamps in the box.

The right external jugular vein was then laid bare, ligated and cut with the heart end prepared for injection of adrenaline solutions as well as of the fluids to be tested for epinephrine concentration, a glass cannula with a thick rubber tube, closed at the opposite end, being inserted and ligated. The rubber tube must be thick, else it will be evidently expanded by the pressure of the injection, the greater the pressure, the greater the dilation, so that it is not possible to make an injection exactly with the designed velocity.

Sometimes the tracheal cannula was laid in order to avoid the occurrence of any mechanical hindrance in the lung ventilation either by rhinitis which not seldom follows the removal of the superior cervical ganglion or by the entering of the romited mass into the trachea of the cat fastened on its back. It is scarcely necessary to add here that urethane frequently plays an emetic action on cats.

In the instances in which the epinephrine output was auto-assayed by the eye reaction, preparation of the cava pocket was now practised. In the other set of the present researches the abdomen was not opened; the blood specimens from the cava pocket made in another cat were determined by means of the paradoxical eye reaction of this cat.

The cat table was fixed on another large table with an arrangement for changing the inclination of the upper plate at will. For collection of the pocket bloods the table was inclined, as a rule, at $15^{\circ}$ with the feet downwards, and for the eye reaction it was inclined at the same angle, but with the head downwards.

Measurement of the paradoxical pupil dilation.

Among the paradoxical eye reactions the dilation of the pupil was precisely measured. Attention was also paid to behavior of the nictating membrane.

The transverse diameter of the pupil was measured by means of a millimeter rule under an electric lamp of 50 candle power. When needed, the eye lids were held apart instrumentally.

Of the pupil reaction the following features were noted: (1) the initial width of pupil, (2) the time and duration when the adrenaline solution or the blood or fluid containing epinephrine was injected in the external jugular vein, (3) the time at which the pupil started to dilate, (4) the time 
at which the dilation reached its maximum, and (5) the maximum width attained. The degree which the maximum width (5) surpasses initial width (1) is the amount of dilation caused by that injection. In addition to these estimations the diameter of the pupil was sometimes taken at 60 , 120 and 180 seconds after starting the injection or the releasing of the upper path of the cava pocket.

In the experiments of several writers, who have studied or made use of this pupil reaction for a rude judgement of the epinephrine output or for a quantitative determination of epinephrine output or of adrenaline, either the amount of dilation ${ }^{6 / 7}$ or the latency of reaction ${ }^{8)}$ was essentially noticed. The time between the injection and the first sign of recovery of pupil and that between the former and the complete recovery of pupil size were also taken in addition to the amount of dilation. ${ }^{6}$

Since a close relationship was invariably found established between the quantity of adrenaline hydrochloride and the amount of pupil dilation in some special experiments in which various quantities of adrenaline hydrochloride were applied, and the above mentioned kinds of estimations were carried out, as illustrated in the following examples, the amount of pupil dilation was particularly followed in the principal experiments in the present paper. Though the time between the start of the injection and the complete recovery of the pupil width to its initial was also found closely related to the amount of adrenaline injected, it can be utilized in the cases of auto-assay only with difficulty, because of the frequent occurrence of the progressive dilation of the denervated pupil in the animal provided with the cava pocket. The other estimations did not given so satisfactory results in our hands as the above two, so that the amount of epinephrine tested was chiefly reduced from the amount of the pupil dilation.

In Example I the initial widths fluctuated only slightly and rather inclined to become smaller with the lapse of time. A progressive diminution in the size of the pupil at intervals was several times observed while adrenaline was repeatedly applied intravenously, and this fact was occasionally utilized in order to check the progressive dilation of the pupil which frequently took place in the cat in which the cava pocket was prepared.

6) D. R. Josep b, J. Exp. Med., 1912, 15, 644.

7) T. R. Elli ot t, J. Physiol., 1912, 44, 399-402; C. H. Kell aw a y, Ibid., 1919(-20), 53, 214-232; F. A. Hartman, H. A. McCordock and M. M. Loder, Am. J. Physiol,, 1923, 64, 1; F. A. Hartman and W. B. Hartman, Ibid., 1923, 65, 612; K. Shimidzu, Schmiedeberg's Arch., 1924, 103, 52.

8) G. N. Stewart, J. M. Rog off and F. S. Gibson, J. Parm. Exp. Ther., 1916, 8, 205 ; G. N. Stewart and J. M. Rogoff, Ibid., 1916, 8, 479; Ibid., 1917(-18), 10, 1; Am. J. Physiol., 1923, 66, 241. 


\section{Example I.}

Effect of various quantities of adrenaline hydrochloride on the

$$
\text { denervated pupil of cat. }
$$

26. VII. 1923. Cat. 우 2.4 kilos.

Right superior cervical ganglion had been excised 16 days previous to the experiment.

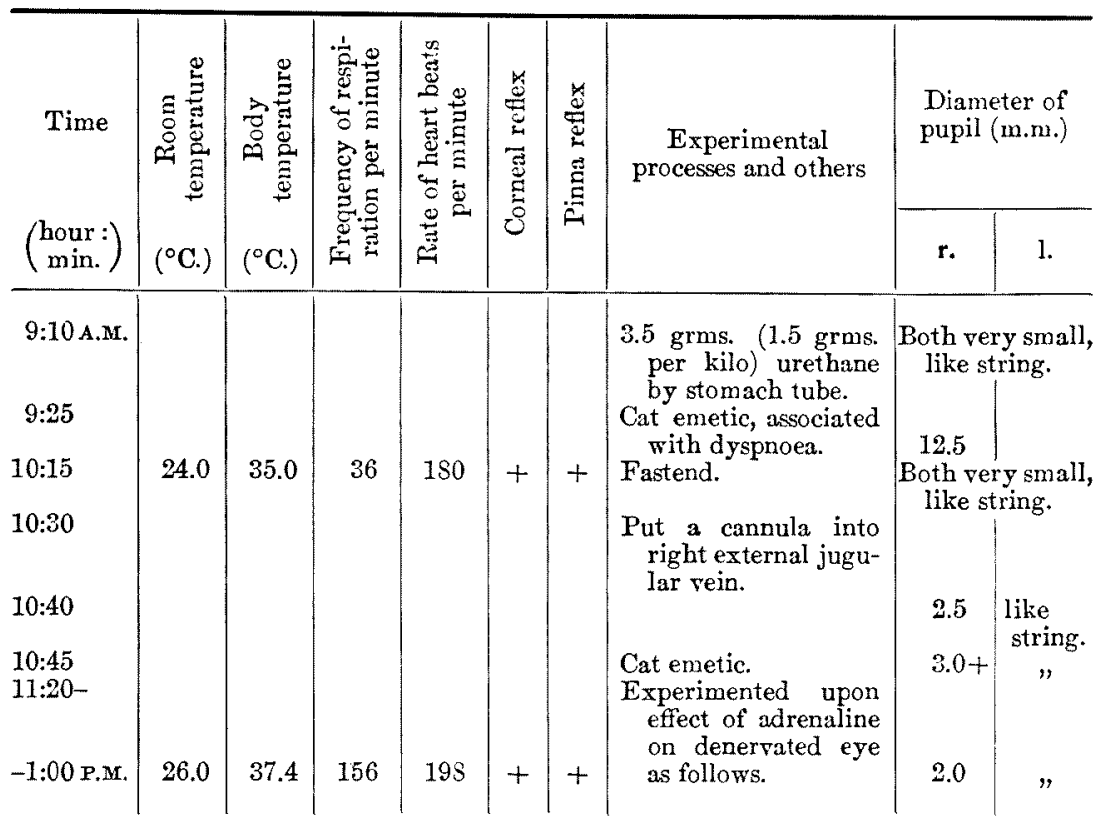

Effect of adrenaline hydrochloride solutions on the denervated pupil:

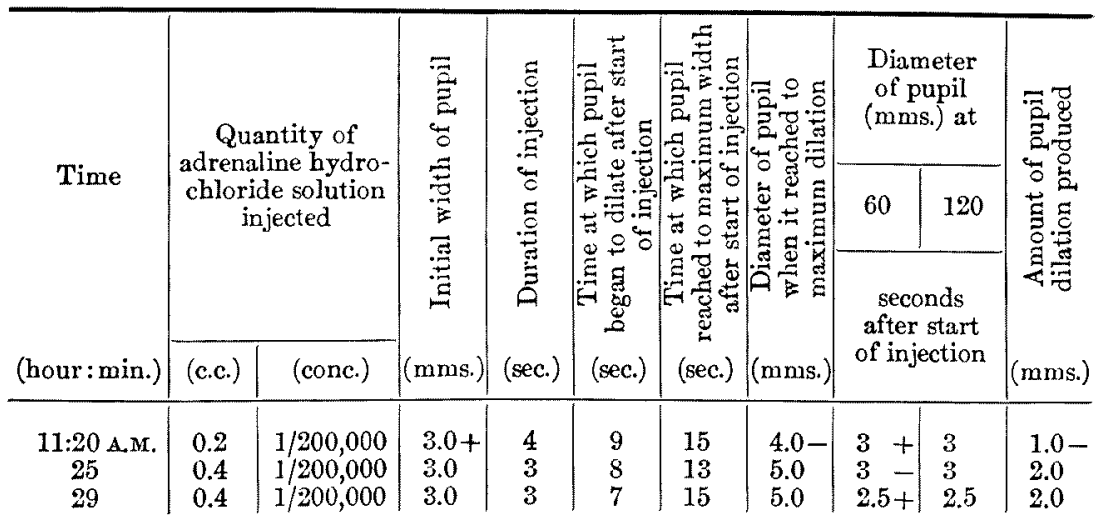




\begin{tabular}{|c|c|c|c|c|c|c|c|c|c|c|}
\hline \multirow[b]{3}{*}{ (hour: $\min$.) } & \multirow{2}{*}{\multicolumn{2}{|c|}{$\begin{array}{l}\text { Quantity of } \\
\text { adrenaline hydro } \\
\text { chloride solution } \\
\text { injected }\end{array}$}} & \multirow{3}{*}{ 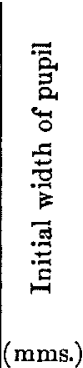 } & \multirow{3}{*}{ 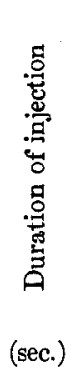 } & \multirow{3}{*}{ 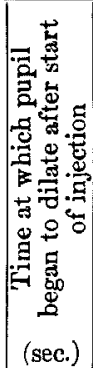 } & \multirow{3}{*}{ 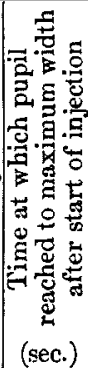 } & \multirow{3}{*}{ 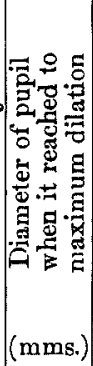 } & \multicolumn{2}{|c|}{$\begin{array}{l}\text { Diameter } \\
\text { of pupil } \\
\text { (mms.) at }\end{array}$} & \multirow{3}{*}{ 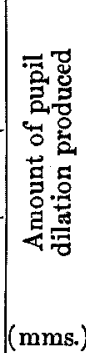 } \\
\hline & & & & & & & & 60 & 120 & \\
\hline & (c.c.) & (conc.) & & & & & & \multicolumn{2}{|c|}{$\begin{array}{c}\text { seconds } \\
\text { after start } \\
\text { of injection }\end{array}$} & \\
\hline 11:33 A.M. & 0.5 & $1 / 200,000$ & 2.5 & 3 & 7 & 15 & $5.5+$ & 3.5 & 2.5 & $3.0+$ \\
\hline & 0.6 & $1 / 20$ & $2.5+$ & 3 & 7 & 16 & $6.5+$ & 3.5 & 2.5 & \\
\hline 41 & 0.6 & $1 / 20$ & 2.5 & 3 & 8 & 14 & $6.0+$ & 3.0 & 2.5 & 3 \\
\hline 46 & 0. & $1 /$ & 2.5 & 3.5 & 8 & 13.5 & $6.0-$ & $3-$ & $2+$ & 3.0 \\
\hline 50 & 0.5 & $1 / 2$ & 2.0 & 3 & 9 & 13 & 5.0 & 3 & 2.5 & 3.0 \\
\hline 5 & 0 & $1^{\prime} / 20$ & 2.5 & 3.5 & 9 & 16.5 & 5. & 3 & 2.5 & \\
\hline 59 & 0 & 1 & 2.5 & 3 & 8.5 & 13 & $5.0-$ & 3 & 3 & 2.5 \\
\hline 12:03 P.M. & 0.4 & $1 / 20$ & $2.5+$ & 4 & 8 & 15 & $4.5+$ & 3 & 2.5 & $2.0+$ \\
\hline 07 & 0. & & 2.5 & 3.5 & 8 & 13.5 & 4.0 & 3 & 2.5 & \\
\hline 12 & 0. & $1)$ & 2.5 & 3.0 & 9 & 13.5 & $3.5+$ & 3 & 2.5 & 1. \\
\hline 16 & 0. & $1 / 2$ & 2.5 & 3 & 9.5 & 15 & $4 .(1$ & $2.5+$ & 2.5 & \\
\hline 20 & 0.2 &, 000 & 2.5 & 3.5 & 8.0 & 13.5 & $4.0-$ & 3.0 & 2.5 & 1. \\
\hline 25 & 0. & $1 / 200,0$ & 2.5 & 3 & 9. & 13.5 & $3.5+$ & 3.0 & 2.5 & 1.0 \\
\hline 30 & 0. & $1 / 200,000$ & $2.0+$ & 3 & 9.5 & 15 & $3.5+$ & $3.0-$ & 2.5 & \\
\hline 35 & 0.5 & $1 / 500,000$ & 2.5 & 3 & 10.0 & 14 & $3.5+$ & 3.0 & 2.5 & 1.0 \\
\hline 40 & 0. & & 2.5 & 3 & 9.0 & 12 & $3.5+$ & 3.0 & $2 . \overline{0}$ & \\
\hline 45 & 0. & $1 /$ & $2.0+$ & 3 & 8 & 11 & $2.5-$ & $2.0+$ & $2.0+$ & 0 \\
\hline 50 & 0.3 & $1 / 500,000$ & $2.0+$ & 3.5 & 0 & 12 & $2.5-$ & $2.0+$ & $2.0+$ & \\
\hline ש & 0.4 & $1 / 200,000$ & $2.5-$ & 4 & 8 & 15 & 4.5 & $2.5+$ & 2.5 & $2.0+$ \\
\hline
\end{tabular}

That the amount of dilation is closely dependent upon the dose of adrenaline is clearly seen from examination of this example. If the numbers be further epitomized as follows, the relation becomes more readily demonstrable :-

$0.0006 \mathrm{mgrm}$. adrenaline caused dilation of $0.5 \mathrm{~mm}$. ( 2 assays)

\begin{tabular}{|c|c|c|c|c|c|}
\hline $0.001 \mathrm{mgrm}$. & & & & $1.0^{-}-1.5^{-}$mms. $(6$ & assays) \\
\hline $0.0015 \mathrm{mgrm}$. & " & $"$ & $"$ & $1.0^{\circ}-1.5$ mus. $(3$ & " \\
\hline $0.002 \mathrm{mgrm}$. & $\because$ & $"$ & $"$ & $2.0-2.5$ mms. 6 & $"$ \\
\hline $0.0025 \mathrm{mgrm}$. & $"$ & $"$ & $"$ & $3.0^{-}-3.0 \div \mathrm{mms} .(3$ & $n$ \\
\hline 0.003 mgrm. & $"$ & " & " & $3.5 \div-4.0$ mms. $(2$ & $"$ \\
\hline
\end{tabular}

While at $11: 20$ A. M. $0.001 \mathrm{mgrm}$. adrenaline hydrochloride evoked a dilation of 1.0-mm., the same dose caused at $12: 20-12: 40$ p.m. a somewhat larger dilation, as

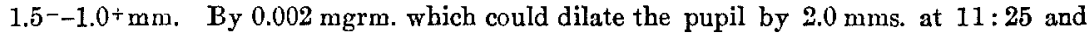
$11: 29$, the pupil was somewhat strongly influenced on later occasions (2.5- mms. at $11: 55 \& 11: 59$ ). Such an inclination, that is the enlargement of the visible effect of adrenaline upon the pupil, though to a small extent, was noticed in the majority of cases. The magnitude of the action of $0.002 \mathrm{mgrm}$. adrenaline was found in this example practically unaltered after one hour. The susceptibility of the denervated pupil to adrenaline commonly undergoes no appreciable alteration within such an interval of time as a half to one hour, as this example shows. On the other hand, however, a great change in the response of the pupil to adrenaline, which makes that preparation quite futile, was met with though infrequently. 
The estimation of epinephrine contained in a fluid injected was made by comparison of the result of that injection only with those of the injections which were separated by a short period of time from that injection.

Some notes in practising the assay of epinephrine content or output by the paradoxical pupil reaction.

On the velocity with which adrenaline solution or the blood or extract for testing is intracenously introduced: These were injected into the right external jugular vein by means of a record syringe. The quantity of fluid introduced by every injection was always dosaged as 1 c.c. to 3 c.c.

On the first trials the influence of variation in the velocity of injection upon the amount of pupil dilation was studied. It was tested by the adrenaline solution of various strengths, which were expected to come into application in the principal investigations of this paper. Something like 1 c.c. in 3 to 10 seconds was found as the optimum velocity. Neither the greater velocity nor the smaller gave satisfactory development of the paradoxical pupil reaction by that dose of adrenaline. One example will be given here.

\section{Example II.}

Effect of the varieties of velocity of injection.

6. VIII. 1923. Cat. 今. 3.3 kilos.

Left superior cervical ganglion had been aseptically excised under ether 10 days before.

8:55 A.Mr. 4.25 grms. (1.3 grm. per kilo) urethane by stomach tube.

10:15 Fastend.

10:19 Put cannulae into trachea and $r$. external jugular vein.

10:35-10:52 Made cava pocket.

11:30 Experimented upon effect of adrenaline hydrochloride solution on the denerrated eye as follows.

\begin{tabular}{|c|c|c|c|c|c|c|c|c|c|c|c|}
\hline \multirow{4}{*}{ Time } & \multirow{3}{*}{\multicolumn{2}{|c|}{$\begin{array}{c}\text { Quantity of } \\
\text { adrenaline } \\
\text { hydrochloride } \\
\text { solution } \\
\text { injected }\end{array}$}} & \multirow{4}{*}{ 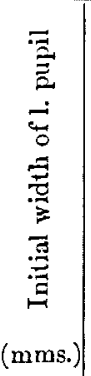 } & \multirow{4}{*}{ 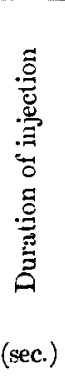 } & \multirow{4}{*}{ 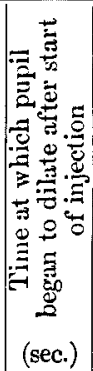 } & \multirow{4}{*}{ 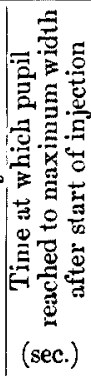 } & \multirow{3}{*}{ 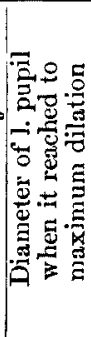 } & \multicolumn{3}{|c|}{$\begin{array}{c}\text { Diameter (mms.) } \\
\text { of l. pupil at }\end{array}$} & \multirow{4}{*}{ 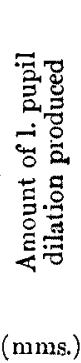 } \\
\hline & & & & & & & & 60 & 120 & 180 & \\
\hline & & & & & & & & \multirow{2}{*}{\multicolumn{3}{|c|}{$\begin{array}{c}\text { seconds after } \\
\text { start of injection }\end{array}$}} & \\
\hline & (c.c.) & (conc.) & & & & & $(\mathrm{mms})$ & & & & \\
\hline $\begin{array}{l}1: 30 \mathrm{~A} \\
34\end{array}$ & 0.5 & $\begin{array}{c}1 / 200,000 \\
",\end{array}$ & $\begin{array}{l}7.5+ \\
6.0\end{array}$ & $\begin{array}{l}2.5 \\
2.5\end{array}$ & $\begin{array}{l}9.5 \\
11\end{array}$ & $\begin{array}{l}17 \\
17.5\end{array}$ & $\begin{array}{l}9.5 \\
8.0\end{array}$ & $\begin{array}{l}7.0 \\
7.5+\end{array}$ & $\begin{array}{l}6.5+ \\
6.5\end{array}$ & $\begin{array}{l}6.5- \\
6.0+\end{array}$ & \\
\hline
\end{tabular}




\begin{tabular}{|c|c|c|c|c|c|c|c|c|c|c|c|}
\hline \multirow{3}{*}{$\begin{array}{c}\text { Time } \\
\left(\begin{array}{c}\text { hour : } \\
\text { min. }\end{array}\right)\end{array}$} & \multirow{2}{*}{\multicolumn{2}{|c|}{$\begin{array}{l}\text { Quantity of } \\
\text { adrenaline } \\
\text { hydrochloride } \\
\text { solution } \\
\text { injected }\end{array}$}} & \multirow{3}{*}{ 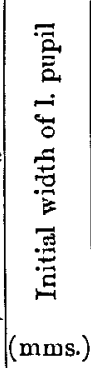 } & \multirow{3}{*}{ 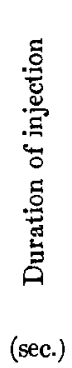 } & \multirow{3}{*}{ 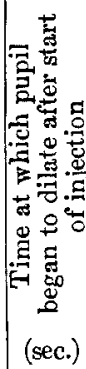 } & \multirow{3}{*}{ 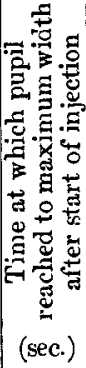 } & \multirow{2}{*}{ 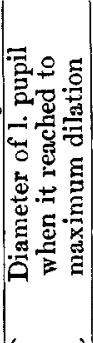 } & \multicolumn{3}{|c|}{$\begin{array}{c}\text { Diameter (mms.) } \\
\text { of l. pupil at }\end{array}$} & \multirow{3}{*}{ 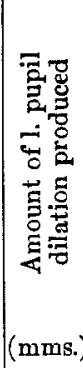 } \\
\hline & & & & & & & & 60 & 120 & 180 & \\
\hline & (c.c.) & (conc.) & & & & & $(\mathrm{mms})$ & \multicolumn{3}{|c|}{$\begin{array}{c}\text { seconds after } \\
\text { start of injection }\end{array}$} & \\
\hline$: 40$ & 0.5 & $/ 200,000$ & $6.0-$ & 5 & 10 & 17 & $9.0+$ & 7. & & 5 & 3.0 \\
\hline & $"$ & & 5.5 & 6. & 12 & I & & & & & \\
\hline 4 & & $"$ & 6.0 & 8 & 12 & 28 & 9. & & & & 3. \\
\hline & " & 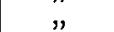 & 6.5 & 14 & 18 & 27.5 & & & & & \\
\hline & $"$ & $"$ & 6.5 & 4 & 11 & 20 & $10.0-$ & & & & \\
\hline & , & 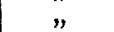 & 7.5 & 2 & 8 & 19 & 10 & & & & 2.5 \\
\hline & ", & " & $7.5+$ & 9 & 14. & 24 & 9. & & & & \\
\hline & 3 & ", & 7.0 & 7. & $\mathrm{I}$ & 20 & 10. & & & & \\
\hline 1 & & 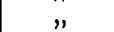 & 6. & 9. & 1 & 23 & & & & & \\
\hline 1. & , & ," & 7.5 & 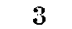 & 10 & 17 & G. & & & & 2.0 \\
\hline 2 & ", & $"$ & 7.5 & 3 & 10 & 17.5 & 10. & & & & \\
\hline & & $"$ & 6.8 & 11 & 10 & 27 & & & & & \\
\hline & & & 6.5 & 13 & 12 & 24 & $9.0-$ & & & & \\
\hline
\end{tabular}

A velocity such as 1 c.c. to 3 c.c. in $3-5$ seconds was adopted through all the experiments in this paper.

That the optimum velocity has such wide limits as 3 to 10 seconds is of high significance in making comparison of a pupil dilation caused by the adrenal vein blood released from the pocket with that evoked by the adrenaline solution which is injected into the jugular vein to cause an equal dilation of the denervated pupil. At any rate it is impossible to follow faithfully and imitate by the injection the time course of entering of the cava pocket blood through the upper cava inferior after releasing the upper path of the pocket. If the optimum velocity had rather narrow limits the comparison might indeed have yielded no available results.

The measurement of the pupil diameter was carried out by myself, the millimeter rule being held at a constant distance from the cornea of the denervated eye. Noting the findings in the pupil size and their time record were done by a technical assistant of this Laboratory. Releasing and clamping of the upper path of the cara pocket and injecting solutions into the jugular vein were also performed by him.

Preparation of adrenaline hydrochloride solution: Adrenaline hydrochloride (preparation of Sankyo \& Co. It was determined for the concentration before use by Kodama's modification of the colorimetric method of Folin, Cannon and Denis.) was diluted first with distilled 
water (not by Ringer or saline solution), and made up in solutions varying in strength $1 / 40 \mathrm{mgrm}$. in 1 c.c., 1/200,1/500 and 1/1000. These were stored in small coloured bottles and kept on ice. The dilution was first made at the beginning of the assays. Just before injection the desired volume was taken from an adrenaline solution with an adequate concentration in a small bottle by means of a small messpipette. Then the double Tyrode (or the double Ringer) was added to it in the same quantity, and by a further addition of Tyrode (or Ringer) the total volume was made as desired, say 1.0-1.5-2.0 c.c. Of this diluted adrenaline-Ringer-solution the desired volume was used for injection.

Tyrode and double-Tyrode (Ringer and double-Ringer) were kept warm in bottles in the water bath at $37-38^{\circ} \mathrm{C}$. In summer time this warming was occasionally saved.

Anaesthesia: Ether. Ether evokes the paradoxical eye reaction. Nowadays there is not the least doubt that this anaesthetic can cause it even in animals deprived of both suprarenal glands. Hartman came to recognize its direct action upon the completely denervated eye itself besides its accelerating influence upon the epinephrine output from the suprarenals. ${ }^{9}$. The action of this narcotic, administered either by inhalation or by direct application to the eye, upon the denervated eye can be detected quite easily, as one protocoll quoted here will demonstrate plainly.

\section{Example III.}

Effect of ether upon denervated eye.

Cat. 우.

21. VIII. 1926. 2.87 kilos. Excised left superior cervical ganglion.

5. X. 1926. 2.17 kilos.

\begin{tabular}{|c|c|c|c|}
\hline \multirow[t]{2}{*}{ Time } & \multicolumn{2}{|c|}{$\begin{array}{l}\text { Diameter of } \\
\text { pupil (mms.) }\end{array}$} & \multirow[t]{2}{*}{ Experimental processes } \\
\hline & 1. & r. & \\
\hline 3:02 P.M. & & & $\begin{array}{l}\text { Urethane } 1.5 \text { grms. per kilo of body weight by sto- } \\
\text { mach tube. }\end{array}$ \\
\hline $3: 54$ & 3.0 & 3.5 & Fastend. \\
\hline $4: 15-6: 14$ & 5.5 & 3.5 & Experimented on the other object. \\
\hline $6: 17-$ & 6.0 & 3.5 & Local application of ether on left eye. \\
\hline $6: 20$ & 8.5 & 3.0 & $\begin{array}{l}\text { Local application of ether off. Both nictitating } \\
\text { membrane prolapsed. Left conjuctiva and nictitat- } \\
\text { ing membrane hyperaemic. }\end{array}$ \\
\hline $6: 22-$ & 6.0 & 3.0 & $\begin{array}{l}\text { Gave ether with W o ulf f's flask by means of tracheal } \\
\text { cannula. }\end{array}$ \\
\hline
\end{tabular}

9) F. A. Hartman, H. A. McCordock and M. M. Loder, Am. J. Physiol., 1923, 64, 29. 


\begin{tabular}{|c|c|c|c|}
\hline \multirow{2}{*}{ Time } & \multicolumn{2}{|c|}{$\begin{array}{l}\text { Diameter of } \\
\text { pupil (mms.) }\end{array}$} & \multirow{2}{*}{ Experimental processes } \\
\hline & 1. & $\mathbf{r}$. & \\
\hline 6:2S P.M. & 12.0 & - & $\begin{array}{l}\text { Left pupil dilated almost to maximum. Left nictitat- } \\
\text { ing nembrane somewhat prolapsed. Right nictitat- } \\
\text { ing membrane prolapsed almost totally, its diameter } \\
\text { measurement impossible. Ether inbalation off. }\end{array}$ \\
\hline
\end{tabular}

Consequently ether cannot be used in anaesthetizing the animal for the determination by the denervated eye reaction.

Urethane. In cats Kellaway, and Hartman and his co-workers detected a small paradoxical dilation caused by urethane. ${ }^{10)}$ The former would attribute this to the direct action of the drug on the plain muscle in the iris. On working with rabbits, Shimidzu was unable to detect any influence of this drug, given in a dose of $0.5-0.75 \mathrm{grm}$. per kilo of body weight, upon the sensitized and atropinized iris.

In most of the cats quoted in the present paper the pupil which was thread like became dilated to about $1 \mathrm{~mm}$. under the influence of urethane in a dose of 1.5 grms. per kilo.

That the epinephrine load of the suprarenals reduces under urethane narcosis and denervation of the gland can largely protect the exhaustion has been established by Elliott on cats ${ }^{11)}$ and by $\mathrm{Hirayama}$ on rabbits. ${ }^{12}$ A ub and his co-adjutors inclined to explain an augmenting effect of urethane upon the metabolism of cats by reference to the effect of the drug upon the suprarenals. ${ }^{13}$ )

For the reason that urethane given in a suitable dose is capable of bringing about a satisfactory anaesthesia of cats, and evolkes no significant action on the sensitized pupil, the drug came into application in the present researches. Here it was of high importance to obviate as far as possible any excitement or any reflex influence upon the epinephrine output as well as upon the paradox.

The sole and grave demerit attendant on the use of this narcotic was its emetic action, which became manifest in a relatively great number of

10) C. H. Kellaway, J. Physiol, 1919(-20), 53, 224; F. A. Hartman, H. A. McCordock and M. M. Loder, Am. J. Physiol., 1923, 64, 4.

11) T. R. Elli ott, J. Physiol., 1912, 44, 391.

12) So. Hir a y a m a, Tohoku J. Exp. Med., 1926, 7, $374 \mathrm{ff}$.

13) J. C. Aub, E. M. Bright and J. Uridil, Am. J. Physiol., 1922, 56, 308; J. C. Aub, E. M. Bright and J. Forman, Ibid., 350 f;; M. A. M cIver and E. M. Bright, Ibid., 1924, 68, $623 \mathrm{f}$. 
cases. Vomiting alone, even when it was not accompanied by any sign of asphyxia, was often followed by the paradoxical eye reaction, though temporarily. When asphyxia was concurrently induced, the pupil dilated largely.

Asphyxia: Asphyxia is one of the most potent agents causing the paradoxical eye reaction. Maximum or nearly maximum dilation is caused with ease by asphyxiating the animal. According to some writers ${ }^{(4)}$ the paradox can be evoked only with difficulty and in a minor degree after removal of the suprarenals, while it was elicited by asphyxia, etc. in the cats of Stewart and Rogoff in which one of the suprarenals had been removed and the nerves of the fellow gland cut with a like ense as in cats the suprarenals of which had not been interfered with. ${ }^{15)}$ Asphyxia accelerates the epinephrine output from the suprarenals. ${ }^{16)}$

At all events asphyxia must be avoided as carefully as possible. Inserting of the tracheal cannula is one example of such care. Rhinitis attendant often on the removal of the superior cervical ganglion and especially vomiting may induce a mechanical hindrance to breathing. Long lasting clamping of the upper path of the cava pocket was often followed by frequent and deep respiration, and concurrently the slowly but steadily developing dilation of the pupil resulted. The paradoxical reaction caused by adrenaline injection both developed and wore off promptly. Attention was paid to the general conditions of the animal, and too long continued clamping of the upper path of the pocket was avoided.

In order to maintain the conditions in the auto-assay experiment as similar as possible at the time of releasing the upper path of the pocket and at that of adrenaline injection the upper path must be clamped during the same period of time as in the releasing experiment. But this procedure is apt to cause the progressive dilation of the pupil; moreover no appreciable difference in the results was occasioned by practising this precaution. So, this procedure was given up in most of the present experiments.

Surgical operations: How the denervated pupil of the urethanized cat is affected by every manipulation attendant on preparing the cava pocket will be exemplified by the instance cited here.

14) T. R. Elliott, J. Physiol., 1912, 44, 402 ; C. H. Kellaway, J. Physiol., 1919 $(-20), 53,225$; F. A. Hartman, H. A. McCordock and M. M. Loder, Am. J. Physiol, $1923,64,13$.

15) G. N. Stew art and J. M. Rog off, J. Exp. Med., 1916, 24, 716 f.

16) Sakuji Koda ma, Tohoku J. Exp. Med., 1924, 5, 47. 


\section{ExAMPLe IV.}

Infuence of operative procedures on the denervated pupil of cat. 29. VI. 1923. Cat. ô. 2.5 kilos.

Right superior cervical ganglion had been removed 23 days prior to the experiment.

\begin{tabular}{|c|c|c|c|c|c|c|c|}
\hline \multirow{2}{*}{ Time } & \multirow{2}{*}{ 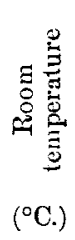 } & \multirow{2}{*}{ 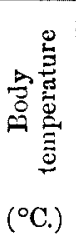 } & \multirow{2}{*}{ 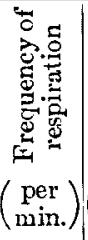 } & \multirow{2}{*}{ 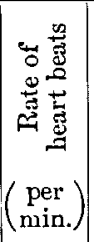 } & \multirow{2}{*}{$\begin{array}{l}\text { Experinental } \\
\text { processes }\end{array}$} & \multicolumn{2}{|c|}{$\begin{array}{l}\text { Diameter of pupil } \\
\text { (mms.) and others }\end{array}$} \\
\hline & & & & & & 1. & r. \\
\hline $9: 15$ A.Mr. & & & & & $\begin{array}{l}3.75 \text { grms. (1.5 grms. } \\
\text { per kilo) urethane by } \\
\text { stomach tube. }\end{array}$ & & \\
\hline $\begin{array}{l}9: 30 \\
9: 33\end{array}$ & 21.0 & 37.1 & 40 & 180 & $\begin{array}{l}\text { Cat emetic. } \\
\text { Fastend. }\end{array}$ & 7.0 & 4.5 \\
\hline $9: 43$ & & & & & $\begin{array}{l}\text { Put cannula into r. ext. } \\
\text { jugular vein. }\end{array}$ & No change & No change. \\
\hline 10:05 & & & & & $\begin{array}{l}\text { Cut the skin of abdo- } \\
\text { men. }\end{array}$ & $"$ & $\begin{array}{l}\text { Dilated mo- } \\
\text { mentarily. }\end{array}$ \\
\hline $10: 06$ & & & & & $\begin{array}{l}\text { Packed the intestine in } \\
\text { hot and moisted } \\
\text { gauze. }\end{array}$ & $"$ & , \\
\hline $\begin{array}{l}10: 07 \\
10: 09\end{array}$ & & & & & Cat struggled a little. & 2.5 & 5.5 \\
\hline $10: 10$ & & & & & $\begin{array}{l}\text { Clamped vena cara be- } \\
\text { low liver. }\end{array}$ & Constant & $\begin{array}{l}\text { Became smaller } \\
\text { a little mo- } \\
\text { mentarily. }\end{array}$ \\
\hline $10: 12$ & & & & & $\begin{array}{l}\text { Released the clamp on } \\
\text { vena cara. }\end{array}$ & & $\begin{array}{l}\text { Became lar- } \\
\text { ger. }\end{array}$ \\
\hline $\begin{array}{l}10: 14 \\
10: 15\end{array}$ & & & & & -. & 2.5 & 5.5 \\
\hline & & & & & $\begin{array}{l}\text { Ligated peripheral end } \\
\text { of r. lumbo-suprare- } \\
\text { na! vein and r. renal } \\
\text { vessels. }\end{array}$ & Constant & $\begin{array}{l}\text { Dilated mo- } \\
\text { mentarily. }\end{array}$ \\
\hline $10: 20$ & & & & & $\begin{array}{l}\text { Ligated peripheral end } \\
\text { of l. Jumbo-suprare- } \\
\text { nal vein and l. renal } \\
\text { ressels. }\end{array}$ & $"$ & $"$ \\
\hline $10: 35$ & & & & & $\begin{array}{l}\text { Ligated coeliac and su- } \\
\text { perior mesenteric ar- } \\
\text { teries. }\end{array}$ & $"$ & $\begin{array}{c}\text { Dilated to } \\
7.0\end{array}$ \\
\hline $10: 38$ & & & & & $\begin{array}{l}\text { Clamped the upper path } \\
\text { of cava pocket. }\end{array}$ & $"$ & No change. \\
\hline $11: 00$ & 21.0 & 38:0 & 16 & 180 & 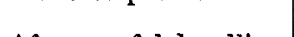 & 2.5 & 7.0 \\
\hline $11: 15$ & & & & & $\begin{array}{l}\text { After careful handling } \\
\text { of the intestine with } \\
\text { newly moisted gauze. }\end{array}$ & 2.5 & 10.5 \\
\hline $11: 40$ & & & & & $\begin{array}{l}\text { Collected cava pocket } \\
\text { specimen after dis- } \\
\text { carded } 6.0 \text { c.c., du- } \\
\text { ring collection of the } \\
\text { specimen dyspnoea } \\
\text { occurred simultane- } \\
\text { ously. }\end{array}$ & 2.5 & 15.0 \\
\hline $10: 42$ & 21.0 & 38.0 & & 82 & $\begin{array}{l}\text { Colour of blood very } \\
\text { dark. }\end{array}$ & 2.5 & $\begin{array}{l}\text { Circular, } \\
\text { maximum. }\end{array}$ \\
\hline
\end{tabular}


Opening of the abdomen, packing the intestines with gauze soaked with a warm saline solution, ligating of vessels, as the renal vessels, the lumbal vein before forming the lumbo-suprarenal vein, coeliac and mesenteric arteries, etc., etc. induced enlargement of the pupil diameter, some more, some less. Preparation of the jugular vein for injection was followed by no trace of dilation. Such a trifling matter usually fails to elicit any visible effect on the sensitised pupil in the urethanized cat.

In an early stage of the experiment closure of the upper path of cara pocket rendered the pupil diameter a little smaller, and the re-opening was succeeded by a dilation.

In most of the cats, in which the cava pocket experiment was carried out, the pupil was apt, as this example shows, to grow progressively wider and to constrict less completely after a dilation by the pocket blood or adrenaline solution. This progressive dilation occurred in 19 cats out of 25 , quoted in Table $\mathrm{I}$. Thus in cats $1,3,7,8,11,13,14,15,22,23$ and 25 in Table $I$, that is in 11 cases out of 25 , the rapid development of this progressive enlargement rendered it impossible to carry out further assays, so that only one auto-assay was done. In some other cats we were moreover unable to undertake any auto-assay because of the excessively rapid development of progressive dilation, as in Exps. on cat 7, 15, 22, 23, 24 and 25 in Table $I$ on p. 376-379.

By reference to the experiments, epitomized in Table I, no definite relationship can be established between the progressive dilation and the rate of epinephrine output.

There was no difference in the rate of epinephrine output between the cases without indicating some sign of the progressive dilation (Exps. 5, 16, $20,21 \& 24$ ), and those qualified by the progressive dilation (the remainder of the cases). Among the latter instances the epinephrine output was successively determined in 12 cats. While in 5 of them (Exps. 4, 9, 11, 12 $\& 15)$ the epinephrine output increased with the lapse of time, though sometimes slowly, the rate of output in the other 7 cats remained without suffering any perceptible alteration throughout the whole course of experiment.

Sensibility of the paradoxical eye reaction: The sensitiveness of the pupil, the superior cervical ganglion to which has been beforehand interfered with, depends upon its actual state of contraction. The smaller the pupil diameter the greater the sensitiveness. The time elapsing after removal of the ganglion is closely related, as is well known, to the sensitiveness of the pupil. It is most sensitive at about the sixth to tenth day after the removal. Commonly it is fairly sensitive till about the end of the third 
week after removal. In 4-6 weeks after the extirpation the sensitiveness is already largely lost.

The double splanchnectomy has merit in respect of the sensibility of denervated pupil, the pupil diameter being remained quite small unless suffering from any special manipulation; this will be refer again later.

The denervated pupil of a cat which can respond to 0.0004 mgrm. adrenaline hydrochloride or to $0.0003 \mathrm{mgrm}$. with a dilation may be taken as a sensitive, good preparation. 'Though seldom we have come across some pupils which could react to an injection of $0.0002 \mathrm{mgrm}$. adrenaline hydrochloride or even to $0.0001 \mathrm{mgrm}$. The denervated eye of every cat, provided it is tested in the sensitive period, is capable of becoming wide in response to a dose of $0.0005 \mathrm{mgrm}$. adrenaline hydrochloride.

In order to exclude any influence by way of the sphincter either removal of the ciliary ganglion (Hartman) or atropinizing ( $\mathrm{Shimidzu}$ ) was exercised. Since the central tonus of the sphincter can be influenced by the carbon dioxide content of the blood,17) the elimination of this mechanism seems desirable under the circumstances. In such a case, it may be worth while to pay attention to the fact that extirpation of the ciliary ganglion is followed by a phenomenon, the paradoxical pupil contraction (not in the old sense of Sch iff ${ }^{18}$ )), which develops very early, and lasts a considerable length of time. ${ }^{19)}$ Cholin can eroke it. But no reference is to be found of its occurrence except by some pharmacological agents.

II.

Parallel Determinations of the Epinephrine Output by the Methods of the Auto-Assay (By the Cava-PocketParadoxical Eye Reaction) and by the CavaPocket-Rabbit Intestine Strip Method.

As stated in the preface, the data reported in 1917 by the Cleveland physiologists that the values of epinephrine output from the suprarenals in cats estimated by the cava-pocket-rabbit intestine segment method were invariably remarkably inferior in comparison with those obtained by the auto-assay (the paradoxical eye reaction evoked after releasing the upper path of the cava pocket) lead us to re-investigate this matter.

The procedures in preparing the cava pocket and the rabbit intestine strip method have been described also in our previous paper. ${ }^{5}$ For practising the eye reaction full accounts are given in the above chapter.

17) H. Wieland and R. Schoen, Schmiedeberg's Arch., 1923, 100, 190.

18) M. Schiff, Gesammelte Beiträge zur Physiologie, III., Lausanne 1896, $118 \mathrm{f}$.

19) H. K. Anderson, J. Physiol., 1905-6, 33, 157-174, \& 416-438; Ryo. Tsulkamoto, Folia Jap. Pharmacol., 1926, 2, 13 (Jap.), Breviaria (German) 2. 
This set of experiments was carried out on 25 cats. Among them we were able to conduct the parallel determinations in 19 cats, while in the rest no auto-assay could be made because of an excessively rapid developing of the progressive dilation of the pupil. Even in eleven out of the successful instances this progressive dilation gave no opportunity to perform the parallel estimations repeatedly.

For illustrating the general course of the experiments one example will be presented in a full account as follows, and the results in 25 cats are summarized in Table I.

\section{Example V.}

8. X. 1923. Cat 9. ̂. 3.0 kilos.

Left superior cervical ganglion was excised 10 days before.

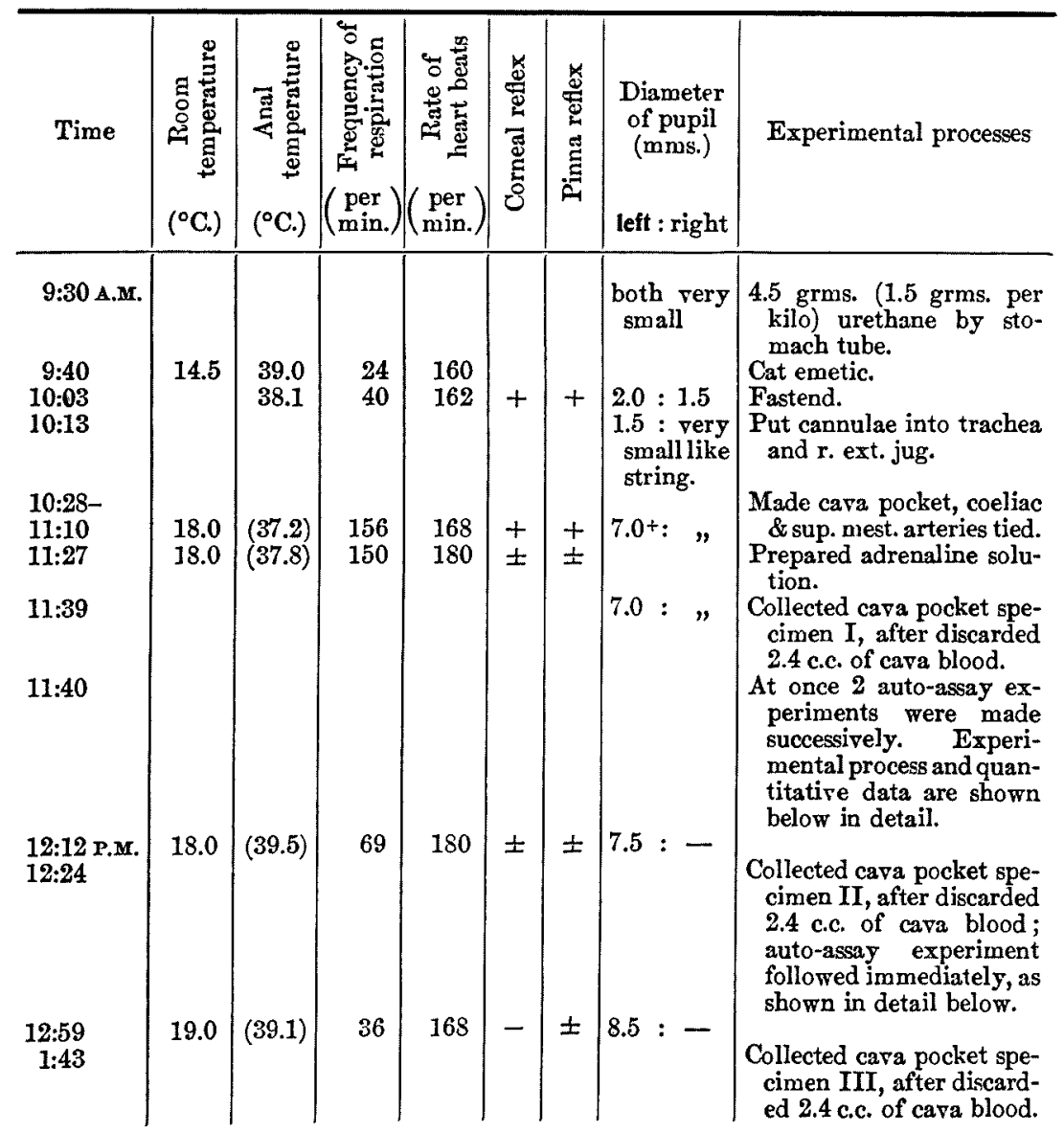




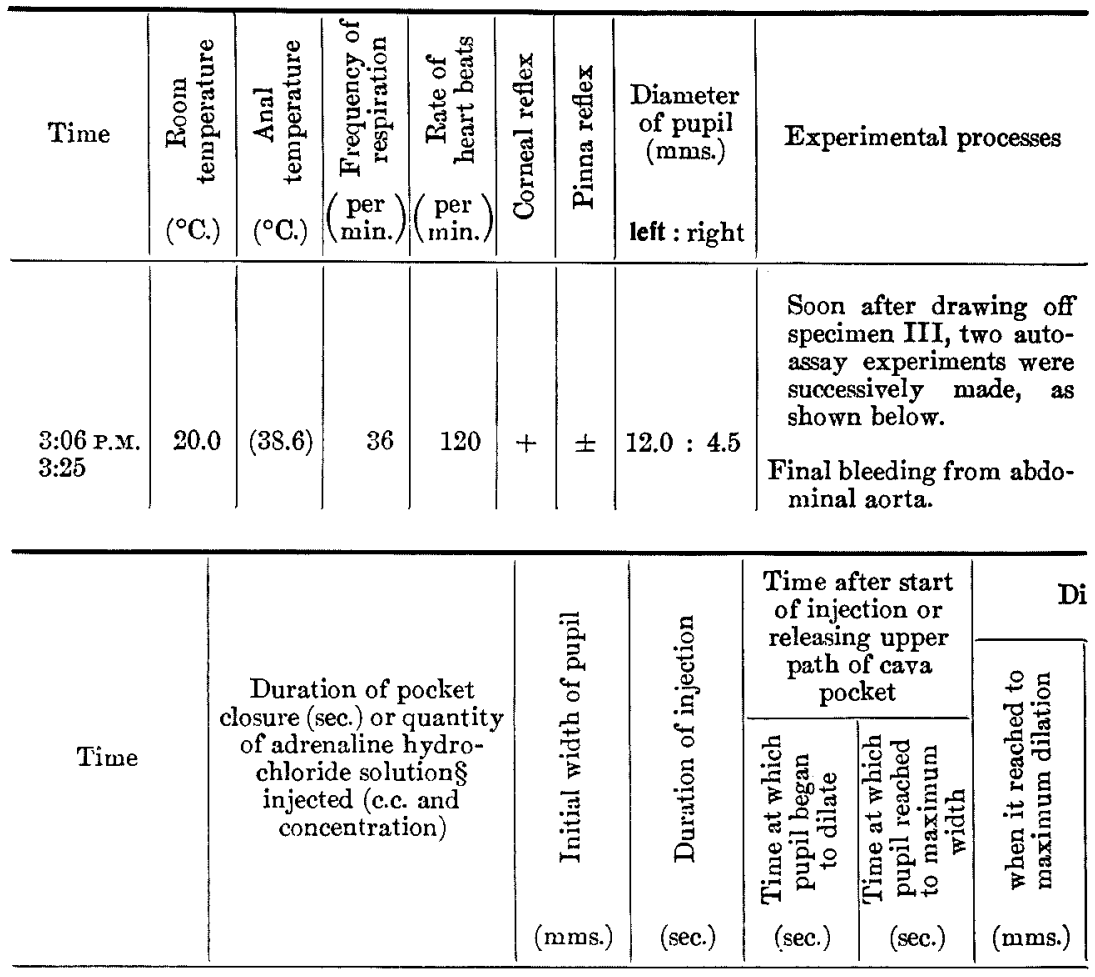

11:39 A.M.

11:40

11:46

11:51

11:55

$11: 59$

12:04 P.Mr.

12:08

12:24 P.Mr.

12:25

12:32

12:38

$12: 43$

$12: 48$

1:43 г...

$1: 45$

1:51

2:03

2:09

$2: 16$

2:25

$2: 34$

2:40

2:50
(I c. p. specimen was collected. Blood flow : 3.3 c.c. per minute.)

\begin{tabular}{|c|c|}
\hline Pocket $\left(\mathrm{I}^{\prime}\right)$ & \\
\hline $\begin{array}{c}\left(\mathrm{I}^{\prime \prime \prime}\right) \\
1 / 200,000\end{array}$ & \\
\hline $\begin{array}{l}1 / 200,000 \\
1 / 200,000\end{array}$ & \\
\hline $1 / 200,000$ & \\
\hline $1 / 200,000$ & \\
\hline $1 / 200,000$ & \\
\hline
\end{tabular}

7.0
7.0
7.5
8.0
7.0
7.0
7.0

\begin{tabular}{r|r|} 
& 9 \\
3.0 & 10 \\
3.0 & 7 \\
3.0 & 10 \\
3.5 & 11 \\
3.5 & 12 \\
\hline
\end{tabular}

11.0

11.0

10.0

12.0

11.0

10.0

12.0

(II c. p. specimen was collected. Blood flow : 1.9 c.c. per minute.)

Pocket (II') 100
$0.31 / 200,000$
$0.51 / 200,000$
$0.5 \quad 1 / 200,000$
$0.451 / 200,000$

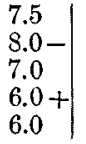

7.5
$8.0-$
7.0
$6.0+$
6.0

16
14
15
15
13

\begin{tabular}{l|l|}
36 & $12.0+$ \\
32 & 11.0 \\
27 & 12.0 \\
28 & 11.0 \\
29 & $10.5-$
\end{tabular}

(III c. p. specimen was collected. Blood flow : 2.0 c.c. per minute.)
Pocket (III') 90
" (III") 90
$0.4 " 1 / 200,000$
$0.51 / 200,000$
$0.451 / 200,000$
$0.4 \quad 1 / 200,000$
$0.31 / 200,000$
$0.41 / 200,000$

$\left|\begin{array}{c}10.5 \\ 11.0 \\ 10.5 \\ 9.5 \\ 10.0+ \\ 9.5 \\ 11.0 \\ 11.0\end{array}\right|$

\begin{tabular}{l|r|l|l|} 
& 8 & 23 & 13.5 \\
3.0 & 7 & 22 & 14.0 \\
3.0 & 13 & 26 & 13.0 \\
3.5 & 13 & 28 & 13.0 \\
3.0 & 15 & 23 & $13.0+$ \\
3.0 & 14 & & \\
3.0 & 17 & 22 & 12.5 \\
& & &
\end{tabular}

$\S$ Adrenaline blood solution which was injected for comparison: Tyrode's solution chloride solution $\alpha$ c.c. 
Paradoxical Eye \& Rabbit Intestine for Assay of Epinephrine Content of Blood 373

Epinephrine output thus determined by auto-assay on Paradoxical eye reaction :

\begin{tabular}{|c|c|c|c|c|c|}
\hline \multirow[b]{2}{*}{$\begin{array}{c}\text { No. of } \\
\text { cava pocket } \\
\text { specimen }\end{array}$} & \multicolumn{3}{|c|}{ Pocket experiment } & \multicolumn{2}{|c|}{ Epinephrine output } \\
\hline & $\begin{array}{c}\text { Duration } \\
\text { of pocket } \\
\text { closure } \\
\text { (min. : sec.) }\end{array}$ & $\begin{array}{l}\text { Amount } \\
\text { of pupil } \\
\text { dilation } \\
\text { (mms.) }\end{array}$ & $\begin{array}{l}\text { Quantity of } \\
\text { adrenaline } \\
\text { which caused } \\
\text { sameamount } \\
\text { of dilation } \\
\text { (mgrm.) }\end{array}$ & $\begin{array}{l}\text { Output per } \\
\text { minute } \\
\text { per animal } \\
\text { (mgrm.) }\end{array}$ & $\begin{array}{l}\text { Output per } \\
\text { minute } \\
\text { per kilo } \\
\text { (mgrm.) }\end{array}$ \\
\hline $\begin{array}{l}\mathbf{I}^{\prime} \\
\mathbf{I}^{\prime \prime} \\
\text { II' }^{\prime} \\
\text { IIII' } \\
\text { III' }\end{array}$ & $\begin{array}{l}1: 30 \\
1: 30 \\
1: 40 \\
1: 30 \\
1: 30\end{array}$ & $\begin{array}{l}4.0 \\
4.0 \\
4.5 \\
3.0 \\
3.0\end{array}$ & $\begin{array}{l}0.002 \\
0.002 \\
0.00237 \\
0.00225 \\
0.00225\end{array}$ & $\begin{array}{l}0.00133 \\
0.00133 \\
0.00142 \\
0.0015 \\
0.0015\end{array}$ & $\begin{array}{l}0.00044 \\
0.00044 \\
0.00047 \\
0.0005 \\
0.0005\end{array}$ \\
\hline
\end{tabular}

\begin{tabular}{|c|c|c|c|c|c|c|}
\hline \multicolumn{3}{|c|}{ ameter of pupil at } & \multirow{4}{*}{ 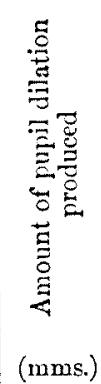 } & \multirow{3}{*}{ 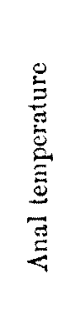 } & \multirow{4}{*}{ 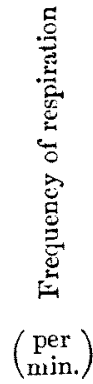 } & \multirow{4}{*}{ 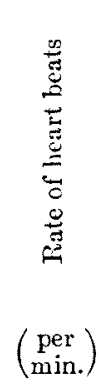 } \\
\hline 60 & 120 & 180 & & & & \\
\hline \multirow{2}{*}{\multicolumn{3}{|c|}{$\begin{array}{l}\text { seconds } \\
\text { after start of injection } \\
\text { or releasing upper } \\
\text { path of cava pocket }\end{array}$}} & & & & \\
\hline & & & & $\left({ }^{\circ} \mathrm{C}.\right)$ & & \\
\hline
\end{tabular}

\begin{tabular}{r|c|c|c|c|c|c}
10.0 & 9.0 & 7.0 & 4.0 & $(38.6)$ & 96 & 168 \\
10.0 & 9.0 & 7.5 & 4.0 & $(38.6)$ & 96 & 168 \\
$9.0+$ & 9.0 & 8.0 & 2.5 & $(39.1)$ & 78 & 192 \\
10.0 & 9.0 & 7.5 & 4.0 & $(39.4)$ & 54 & 180 \\
10.0 & 9.0 & 8.0 & 4.0 & $(39.6)$ & 48 & 180 \\
9.0 & 8.0 & 7.5 & 3.0 & $(39.7)$ & 66 & 180 \\
10.0 & 8.5 & 7.5 & 5.0 & $(39.5)$ & 69 & 180
\end{tabular}

\begin{tabular}{r|r|l|l|l|l|l} 
& 10.0 & 8.5 & $4.5+$ & $(39.7)$ & 84 & 192 \\
9.5 & 8.5 & 9.5 & 3.0 & $(39.8)$ & 84 & 180 \\
10.0 & 8.5 & 7.0 & 5.0 & $(39.8)$ & 60 & 180 \\
8.0 & 7.0 & 6.0 & $5.0-$ & $(39.8)$ & 44 & 168 \\
$8.5+$ & 8.0 & 6.5 & $4.5-$ & $(39.8)$ & 48 & 180
\end{tabular}

\begin{tabular}{c|c|c|c|c|c|c}
13.0 & 12.0 & 11.0 & 3.0 & $(38.6)$ & 54 & 168 \\
& 11.5 & 10.5 & 3.0 & $(38.6)$ & 42 & 180 \\
12.0 & 11.0 & 10.5 & 2.5 & $(38.5)$ & 38 & 168 \\
12.5 & 11.0 & $10.0+$ & 3.5 & $(38.5)$ & 42 & 192 \\
12.5 & 11.5 & $10.0-$ & 3.0 & $(38.4)$ & 36 & 162 \\
Cat emelic. & & & & $(38.5)$ & 36 & 120 \\
11.5 & 11.0 & 11.0 & 1.5 & $(38.5)$ & 36 & 156 \\
& \multicolumn{2}{|c|}{ Cat romited } & & $(38.4)$ & Asphyxia & 90 \\
& \multicolumn{2}{|c|}{} & & & 20 & 180
\end{tabular}

1.0-2 $\alpha$, double Ty rod e's solution $\alpha$ c.c. and adrenaline hydro-
The drawn blood from cava pocket specimen I, II and III were assayed from 4:30 p.m. to $9: 05$ p.m. on rabbit intestine strip. Quantitative results as follows :

Sample I: Stronger than 0.0003 mgrm. per 0.5 c.c. ; stronger than 0.00035 mgrm. per 0.5 c.c. (2 assays); weaker than 0.4 mgrm. per 0.5 c.c. I was taken at 0.00075 ingrm. per 1 c.c.

Sample II: Weaker than $0.00 \mathrm{I}$ mgrm. per 0.5 c.c.; stronger than 0.0005 mgrm. per 0.5 c.c.; as strong as 0.00075 mgrm. per 0.5 c.c. II was assayed at 
0.0015 mgrm. per 1 c.c.

Sample III : Weaker than 0.0015 mgrm. per 0.5 c.c.; stronger than 0.0005 mgrm.; weaker than 0.001 mgrm.; not much different from 0.00075 mgrm. III was assayed at 0.0015 mgrm. per 1 c.c.

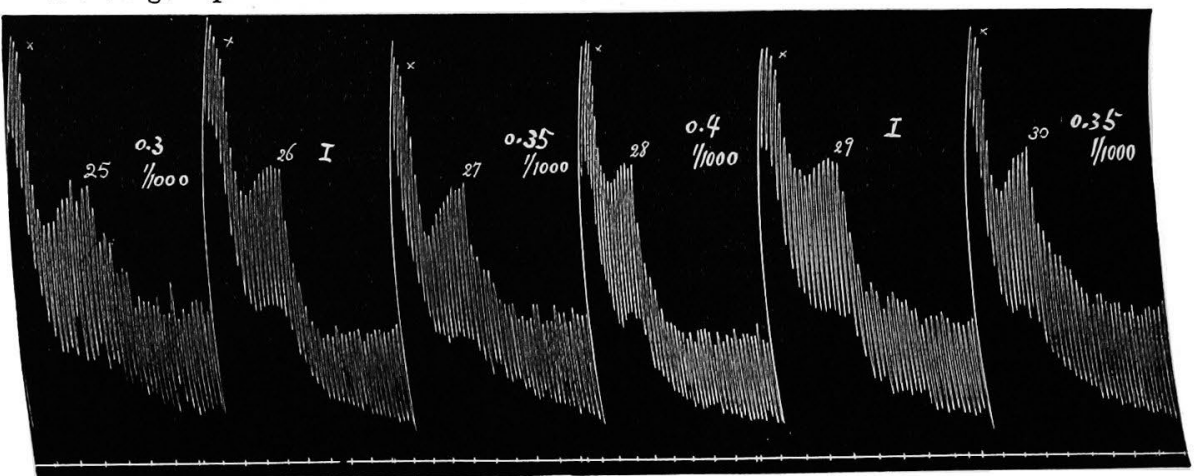

Fig. 1. a. $\S$ At $25,27,28$ and 30 adrenaline blood solutions which contained 0.3 c.c., 0.35 c.c., 0.4 c.c. and 0.35 c.c. of adrenaline hydrochloride solution in strength of $1: 1,000,000$ per 0.5 c.c. were respectively applied.

At 26 and 29 I cava pocket specimen solution was applied.

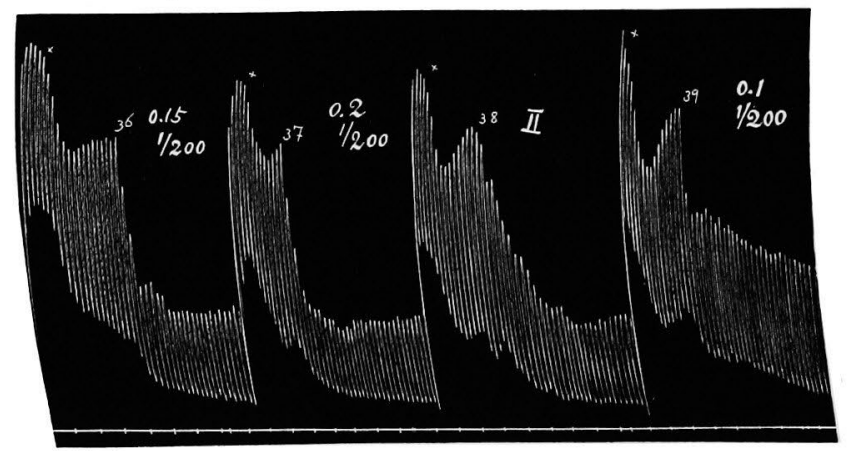

Fig. 1. b. At 36, 37 and 390.15 c.c., 0.2 c.c. and 0.1 c.c. of adrenaline hydrochloride solution in strength of $1: 200,000$ per 0.5 c.c. were respectively applied. At 38 II cava pocket specimen solution was applied.

$\S$ In all the intestine tracings, at the mark " $x$ " atropin-T y rod e's solution, in which the rabbit intestine segment was beating rbythmically, was replaced by indifferent blood solution, and at the "numeral" the indifferent blond solution was displaced by adrenaline blood solution, that is, the indifferent blood solution to which a certain quantity of adrenaline chloride of Sankyo \& Co. was added, or by the cava pocket blood solution. All the blood solutions were prepared by diluting with 4 volumes of Tyrode's solution and the quantity of the bloods employed for one assay was 0.5 c.c.

In all tracings, time intervals 30 seconds. 


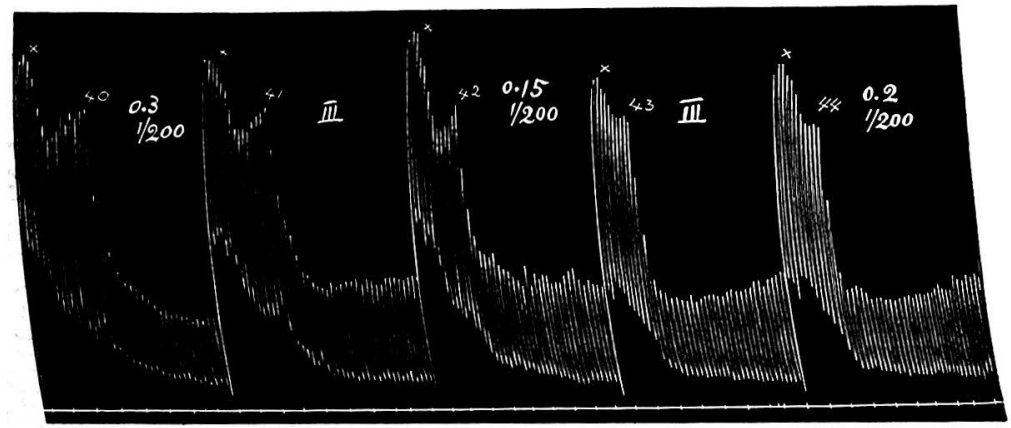

Fig. 1. c. At 40,42 and 440.3 c.c., 0.15 c.c. and 0.2 c.c. of adrenaline bydrochloride solution in strength of $1: 200,000$ per 0.5 c.c. were respectively applied. At 41 and 43 III cara pocket specimen solution was applied.

Epinephrine output determined by rabbit intestine strip :

\begin{tabular}{|c|c|c|c|c|c|c|c|}
\hline \multirow{3}{*}{$\begin{array}{c}\text { No. of } \\
\text { cava } \\
\text { pocket } \\
\text { specimen }\end{array}$} & \multicolumn{4}{|c|}{ Blood flow (c.c.) } & \multicolumn{3}{|c|}{ Epinephrine output (mgrm.) } \\
\hline & \multirow{2}{*}{ Quantity } & \multirow{2}{*}{$\begin{array}{c}\text { Duration } \\
\text { of } \\
\text { collection } \\
\text { (sec.) }\end{array}$} & \multicolumn{2}{|c|}{$\begin{array}{l}\text { Quantity } \\
\text { per minute }\end{array}$} & \multirow{2}{*}{$\begin{array}{l}\text { Quantity } \\
\text { contained } \\
\text { in } 1 \text { c.c. }\end{array}$} & \multicolumn{2}{|c|}{$\begin{array}{c}\text { Output } \\
\text { per minute }\end{array}$} \\
\hline & & & $\underset{\text { animal }}{\text { per }}$ & $\begin{array}{l}\text { per } \\
\text { kilo }\end{array}$ & & $\begin{array}{c}\text { per } \\
\text { animal }\end{array}$ & $\begin{array}{l}\text { per } \\
\text { kilo }\end{array}$ \\
\hline $\begin{array}{l}\text { I } \\
\text { III }\end{array}$ & $\begin{array}{l}2.2 \\
1.9 \\
2.0\end{array}$ & $\begin{array}{l}40 \\
60 \\
60\end{array}$ & $\begin{array}{l}3.3 \\
1.9 \\
2.0\end{array}$ & $\begin{array}{l}1.1 \\
0.6 \\
0.7\end{array}$ & $\begin{array}{l}0.00075 \\
0.0015 \\
0.0015\end{array}$ & $\begin{array}{l}0.00247 \\
0.00285 \\
0.003\end{array}$ & $\begin{array}{l}0.00082 \\
0.00095 \\
0.0010\end{array}$ \\
\hline
\end{tabular}

Ratio of the two assays :

\begin{tabular}{|c|c|c|c|}
\hline \multirow{2}{*}{ No. of specimen } & \multicolumn{2}{|c|}{$\begin{array}{c}\text { Epinephrine output } \\
\text { per animal and per kilo (mgrm.) }\end{array}$} & \multirow{2}{*}{$\begin{array}{c}\text { Ratio } \\
\text { (Pupil : Intestine) }\end{array}$} \\
\hline & pupil & intestine & \\
\hline $\begin{array}{c}I^{\prime} \& I^{\prime \prime} \\
I^{\prime}\end{array}: \underset{I I}{I}$ & $\begin{array}{l}0.00044 \\
0.000475 \\
0.0005\end{array}$ & $\begin{array}{l}0.00082 \\
0.00095 \\
0.0010\end{array}$ & $\begin{array}{l}1: 1.8 \\
1: 2.0 \\
1: 2.0\end{array}$ \\
\hline
\end{tabular}


TABLE

Parallel determinations of the epinephrine output by the eye reaction) and by the cava-pocket-

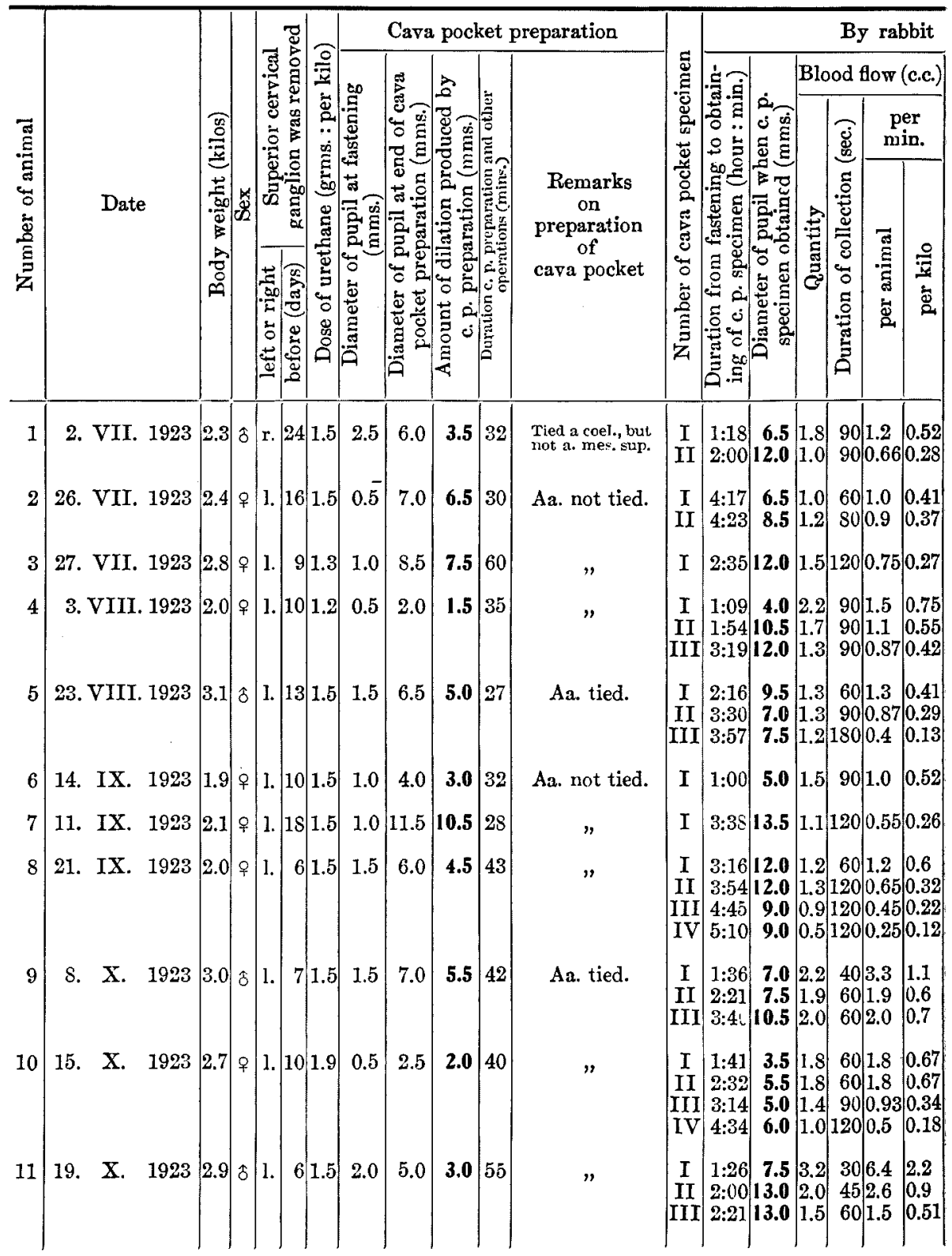


I.

methods of the auto-assay (by the cava-pocket-paradoxical rabbits intestine segment method.

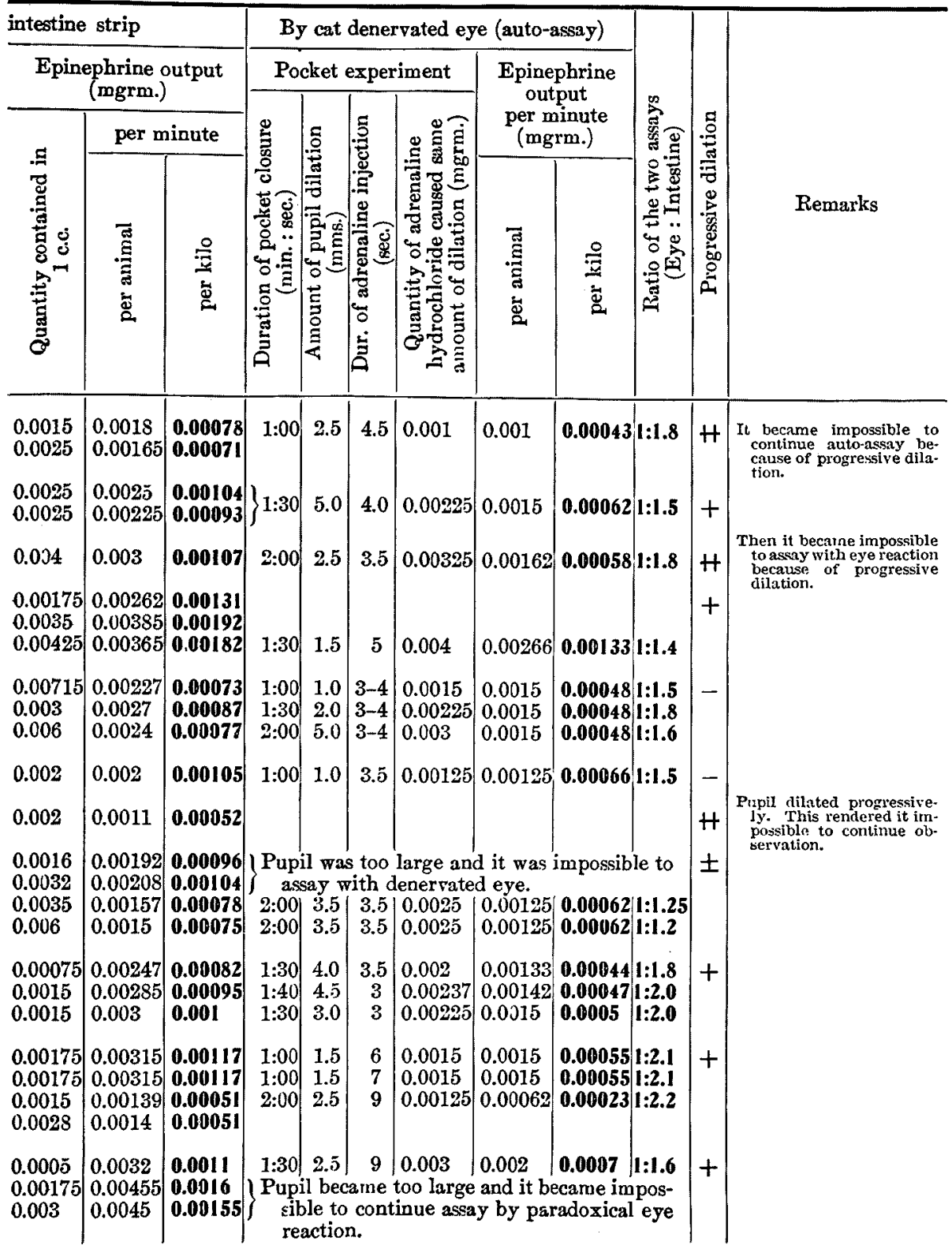



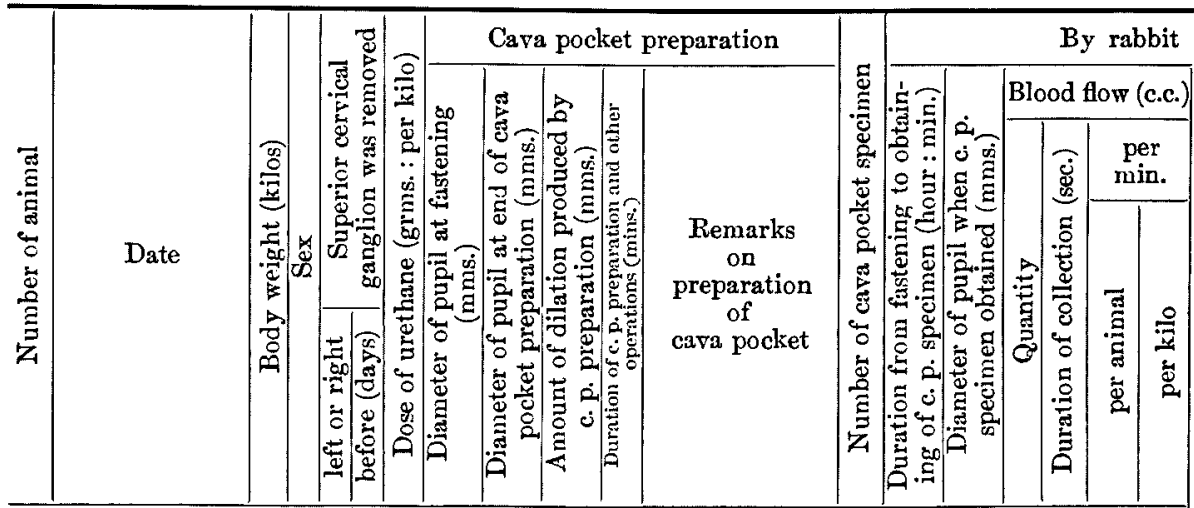

12

13

14

15

16

17

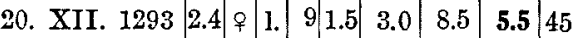

20

22

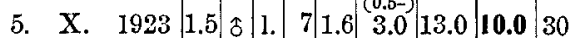

23

24

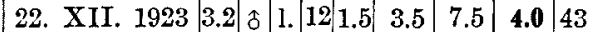

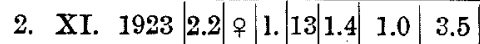

29. XI. 1923 4.2

1. XII. $1923 \quad 4.2$ คे 1.141 .21 .0

11. XII. 1923 2.1 $\hat{o}$ I. 12 1.5 1.0

18. XII. 1923 4.7 ㅇ 1 l. $181.3 \quad 2.0$

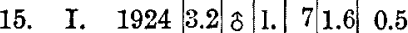

28. IX. 19232.5 우 $1 . \quad 6 \quad 1.5 \quad 4.5$

6.5

2.038

5.510

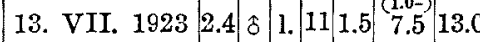

16. VII. 19232.4 o l. 13 (1.0-)

\begin{tabular}{l|l|l}
9.0 & 1.5 & 25
\end{tabular}

\begin{tabular}{l|lll|l|l|l|l|l|l|l|}
25 & 27. VI. 1923 & 2.3 & o & r. & 17 & 1.2 & 2.0 & 12.5 & 10.5 & 41
\end{tabular}
Aa. tied.

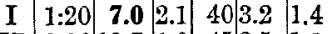

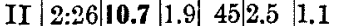

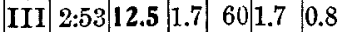

\begin{tabular}{llll|l|l|l|l|l|l} 
I & $1: 11$ & $\mathbf{9 . 0}$ & 2.0 & 60 & 2.0 & 0.47
\end{tabular}

\begin{tabular}{lllllll|l|l} 
I & $1: 04$ & $\mathbf{7 . 0}$ & 3.0 & 60 & 3.0 & 0.7
\end{tabular}

\begin{tabular}{l|llllllll} 
Aa. not tied. & I & $1: 08$ & 6.5 & 2.1 & 60 & 2.1 & 1.0
\end{tabular}

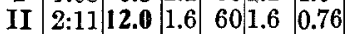

\begin{tabular}{ll|l|l|l|l|l|l} 
III & $2: 31$ & 13.5 & 1.1 & 60 & 1.1 & 0.52
\end{tabular}

$\begin{array}{llllllll}\text { I } & 1: 25 & 8.5 & 3.2 & 30 & 6.4 & 1.3\end{array}$

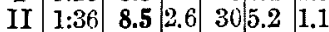

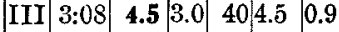

$\begin{array}{lllllllll}\text { I } & 2: 12 & \mathbf{6 . 0} & 1.6 & 90 & 1.0 & 0.3\end{array}$

\begin{tabular}{lll|l|l|l|l|} 
II & $\mathbf{2 : 4 4}$ & $\mathbf{5 . 5}$ & 0.9 & 60 & 0.9 & 0.28 \\
\hline
\end{tabular}

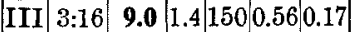

\begin{tabular}{l|l|l|l|l|l|l|l} 
Aa. not tied. & I & $1: 27$ & 5.5 & 1.2 & 60 & 1.2 & 0.48
\end{tabular}

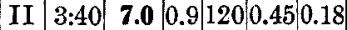

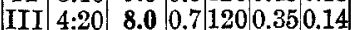

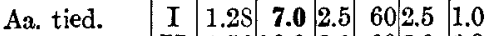

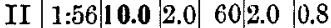

III $4: 18$ 11.0 $2.1 \quad 602.10 .8$

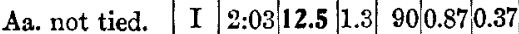

II $2: 40$ I 1.0 1.2 1000.720 .3

$\begin{array}{lllllllll}\text { I } & 1: 2 S & 7.0 & 1.7 & 90 & 1.1 & 0.47\end{array}$

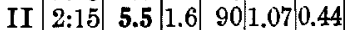

III $3: 01$ 5.0 1.8 90 1.130 .46

$\begin{array}{lllllllll}\text { IV } & 4: 0 S & \mathbf{5 . 0} & 2.0 & 120 & 1.0 & 0.4\end{array}$

I $\quad 2: 0313.00 .51800 .170 .11$

\begin{tabular}{ll|lll|l|l|l} 
Aa. tied. & I & $4: 00$ & 11.5 & 0.8 & 120 & 0.4 & 0.2
\end{tabular}

$\begin{array}{llllllll}\text { A. mes. sup. tied, I } & 1: 24 & 10.0 & 2.2 & 30 & 4.4 & 1.4\end{array}$

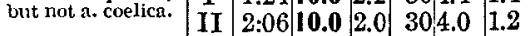

III $3: 02$ 11.0 1.1 90 0.730 .23

\begin{tabular}{l|lll|l|l|l|l|} 
Aa. ligated. I & $1: 38$ & 12.5 & 2.5 & 60 & 2.5 & 1.09
\end{tabular} 


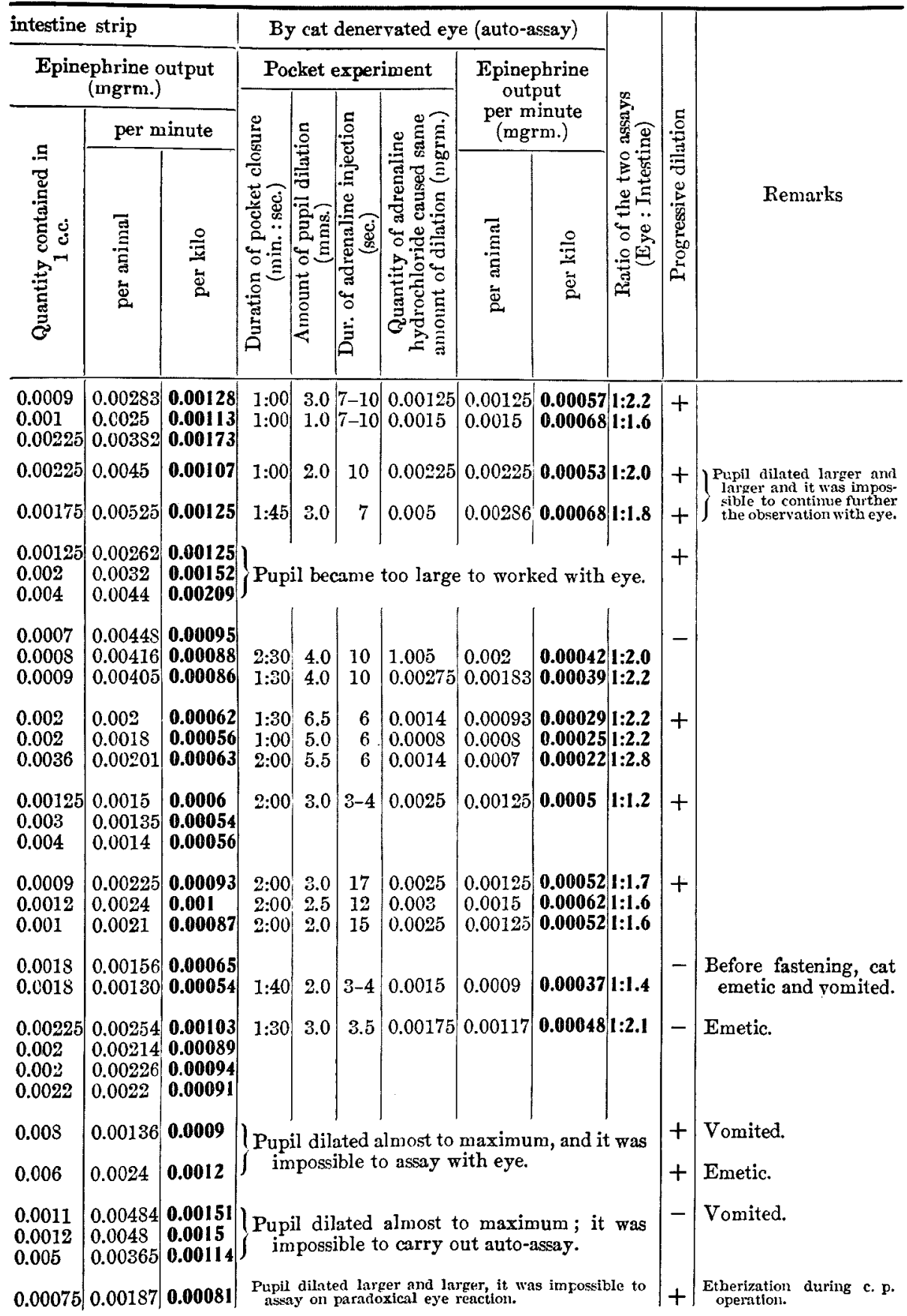


To the cat, one (usually the left) superior cervical ganglion of which was extirpated one to two weeks before, urethane was stomachically given in a dose of 1.5 grms. per kilo of body weight. A half to one hour later, that is when anaesthesia had developed to a somewhat sufficient degree, the animal was fastened on his back on the table. The right external jugular vein was uncovered, and, if wanted, a cannula was put in the trachea, then the cava pocket was prepared on opening the abdomen, the coeliac and superior mesenteric arteries being sometimes ligated. After preparing the adrenaline solutions in several strengths by diluting with distilled water, the first cava pocket specimen was collected for determination by the intestine strip method, preceded by discarding of a certain volume of blood, which somewhat exceeded the dead space of the pocket cannula. Now, the auto-assay was carried out once or twice. That is, the under path of the pocket was clipped, so that the blood from the suprarenal vein accumulated in the cava pocket for a given period of time, say 60,90 or 120 seconds. Then the upper path was released, thereby the paradoxical pupil dilation resulted. Several features in the dilation process was exactly noted. Injection of the adrenaline solutions was then performed in order to follow exactly the dilation process evoked after releasing of the upper path, especially its amount, that is the difference between the initial width and the maximum diameter reached by releasing the pocket. The length of time in which each injection was made was, as a rule, 3-10 seconds, in most cases 3-5 seconds. This leugth of time was most effective in evoking the paradoxical eye reaction by a given amount and concentration of adrenaline as employed in the present investigations; and in fact so chosen to allow the paradoxical dilation to set in with about the same latency as after releasing the pocket. Difference of the injection time as from 3 seconds to 10 seconds had no appreciable affect in the amount of dilation produced. Only in cat 19 the injections was made slowly as $12-17$ seconds. The results in this cat fell also into line with those obtained in the remaining instances.

When the pupil remained in a good condition, that is when the progressive dilation did not develope so rapidly, another set of experiments of the same character as above was repeated.

The blood specimens drawn out from the cava pocket were afterwards assayed by the rabbit intestine segment.

Turning now to the example given above some words may be added. The diameter of the denervated eye in Example $V$ was measured immediately after fastening as 2 mms. For this small dilation the emesis might be accounted. In Cats $20,21,22,23$ and 24 in Table I emesis or 
vomiting was immediately succeeded by a sudden dilation of a somewhat high degree as from 0.5-1.0 mm. (shown in brackets in the table) to 2.5 7.5 mms. A slight asphyxia which accompanied to emesis or vomiting may be taken as immediately responsible for this paradoxical reaction following emesis or vomiting. In two cases, Cats 18 and 19 in Table I, in which the pupil which increased to 4.5 respectively $3.0 \mathrm{mms}$. on fastening, anaesthesia was sufficiently deep and there was not the least indication of emesis.

The smaller the pupil, the more sensitive the paradoxical reaction. It is therefore highly desirous to retain the pupil as small as possible throughout the whole course of the experiment. In the auto-assay experinents the denervated pupil often inclined to become wider and wider.

In this set of experiments compared with those quoted in our other papers more time was consumed in preparing the cava pocket, since attention was paid to the conditions of the pupil from time to time during the preparation. In Example V 57 minutes were spent in the preparation. Preparation of the cava pocket resulted in a paradoxical dilation of a fairly great extent. The duration of time spent in the preparation apparently had no immediate bearing upon the degree of the paradox. In the example the coeliac and superior mesenteric arteries were tied, but in some other experiments in Table I they remained without being ligated. Such a dissimilarity in procedures caused no appreciable difference in the main results studied in the present investigations.

The width of pupil before releasing the upper path of the pocket and those prior to the injection of adrenaline solutions which are to be compared with it must be as much as possible the same. In the examples quoted here the width of pupil prior to application of epinephrine or adrenaline remained fairly constant, sometimes quite constant during each autoassay.

Releasing the upper path of pocket was followed by the parados commonly in 10-15 seconds, sometimes a little less, sometimes a little more. A large delay of this latency, as 30 seconds or more, if occurring, should be accounted for by a retardation of flowing, in any way, of the pocket blood into the general circulation.

As in the example, the collection of the cava pocket blood in the glass cylinder, clamping both the paths of pocket for a given time and subsequent releasing of the upper path, and injections of adrenaline solutions for comparison must be done in succession, while the conditions of the animal do not undergo any noticeable alteration; otherwise anything like an exact comparison would certainly be difficult. 
Commonly the releasing of the upper path of pocket, which was done once or sometimes twice in succession, was followed by repeated injections of adrenaline solutions for the exact matches. In a few cases, however, the releasing of the upper path was intervened once more between the injections of adrenaline solutions for the sake of exactness.

In most cases the upper path of the pocket was not closed during the injections of adrenaline solutions. A long lasting closure of the upper path inclined to call forth the progressive dilation of pupil. Only in every series of determinations in Cat 17 the upper path remained closed during the injections of adrenaline solutions the results, that is the ratios of the value obtained by the segment method and that by the auto-assay, did not fall outside the limits found in the remaining cats.

Now the results obtained in 32 observations on 19 cats will be epitomized as follows :

The epinephrine output per minute and per kilo of body weight was estimated by the auto-assay (the denervated pupil reaction was utilized) as $0.00022-0.00133$ mgrm., on an average 0.00052 mgrm., while the external assay (the cava pocket blood was estimated by the rabbit intestine segment outside of the cat's body) yielded it as 0.00051-0.00191 mgrm., mean $0.00093 \mathrm{mgrm}$. The ratio of these two assays, i.e. eye : intestine ranged from $1: 1.2$ to $1: 2.8$. In the majority of cases it was $1: 1.5-1: 2$, the average being $1: 1.7$. There was no case where the value obtained by the pupil exceeded that by the segment.

As already related in the preface, this ratio well coincides with that of the values newly reported by Stewart and Rogoff. In the five cats newly reported by them, the ratio was $1: 1.2-1: 1.9$, mean $1: 1.5$.

If cat 814 , which received ether, be excluded from the calculation, the mean ratio remained as $1: 1.5$. Ether acts to dilate upon the denervated eye by itself, as stated in the previous chapter, without the corroboration of the suprarenal glands.

Such a close agreement may be taken as accidental, for the number of experiments quoted in the paper of the Cleveland physiologists is by no means large enough for such a comparison. That the experimental data yielded in the hands of the Cleveland physiologists have the same tendency as ours can not be doubted however.

How may such a discrepancy between the results of the auto-pupilassay and the external-rabbit-segment-assay be explained ?

It is beyond doubt, that in making injections of adrenaline fluids for the comparison, there are some dissimilar conditions, compared with the 
releasing of the upper path of the pocket. The introduction of the adrenaline solutions can not be made, for example, at precisely the same rate as that of the suprarenal vein blood after releasing the upper path ; etc., etc.

In oxder to explain the apparent discrepancy between the results of the pupil and segment estimations obtained in their earlier observations, in which the values obtained by the segment method were about half of those by the pupil method, quite contrary to their new data, Stew art and Rog off inferred that the pupil observations cannot be made with the same accuracy as the segment assays. Some reasons were given. The dissimilarity of rates of introductions, as above discussed, is one of them.

Whether such a dissimilarity of condition or conditions is responsible for this difference in the values according to the different methods employed in the present investigations or whether there is another source accountable for this divergency will be answered in the following chapter.

\section{III.}

Parallel Determinations of the Epinephrine Content of the Suprarenal Vein Blood Taken Outside of Cat Body by the Cat Paradoxical Eye Method and the RabBit Intestine Segment Method.

In attacking the problem above referred to the experiments, as the heading of this chapter shows, were performed, and clear information was obtained, we believe, on the main point under discussion.

The suprarenal vein bloods were collected from cats under urethane or ether, the cava pocket being prepared. In some cats, in order to obtain somewhat higher concentration of epinephrine, massage of the suprarenal glands was tried. In one cat nicotine was administered; the results thoroughly corroborate those published on a former occasion. ${ }^{20)}$

Each blood specimen, which was at once defibrinated and placed in a dark cold box, was assayed for epinephrine content by both methods, that is, the paradoxical eye and the rabbit intestine strip. Since the rate of blood flow from the cava pocket was measured, the output of epinephrine may be readily calculated.

For the paradoxical eye reaction the cats were prepared beforehand. One (usually the left) superior cervical ganglion was remored about one to three weeks before the determination. In a few cats the splanchnic nerves, major and minor, were interfered with on both

20) Tadashi Sugawara, Tohoku J. Exp. Med., 1925, 6, 430. 
sides; the cutting was done extraperitoneally either at once or one after another with an interval of a few weeks. Ganglionectomy was conducted one or three weeks after the second splanchnectomy.

Now the cat with a denervated eye was handled as described in the previous chapter, but the abdomen was not opened. The denervated pupil remained quite or somewhat small, and fluctuated but little, contrary to the case of the cats, in which the cava pocket was further prepared.

At first some solutions of varying amount of adrenaline hydrochloride were introduced in a dose as 1 c.c., 2 c.c. or 3 c.c. in the right external jugular vein under a similar and uniform velocity. The paradoxical dilations were carefully taken. Then the cava pocket specimen, diluted by the same or double or half volume of Tyrode, was injected in a dose as 1 c.c., 2 c.c. or 3 c.c. according ability of the pocket blood in dilating the pupil ; now from these results a new quantity of adrenaline was applied, the each total amount being taken as that of the pocket blood solution just introduced.

By repeating and advancing such an injection the epinephrine content of the cava pocket specimen was determined.

The quantities of injected fluids were chosen as small as possible so that the mechanical disturbances towards the blood circulation system might be minimized as much as possible. Adrenaline hydrochloride solution, diluted with distilled water to a given strength, was taken, as a rule, less than 0.5 c.c., the same volume of double Tyrode was now added to it, and then the total quantity was made as 1.0 c.c. by adding Tyrode. To it the indifferent blood of the animal, from which the cava pocket specimen was collected, was further added in the same dose with the cava pocket sample applied for the determination, as $0.5-1.0-1.5$ or 2.0 c.c.

In this kind of experiment the conditions under which both methods were carried out were much more advantageous in comparison with the former sort of experiments. That is, firstly the denervated pupil held its diameter very or pretty small and did not vary so abruptly, so that the initial width, i.e. diameter prior to each injection remained practically unchanged during an ample length of time. So the pupil was highly sensitive and comparison of the effects of the successive injections, could be made without difficulty. Secondly, the introduction of the suprarenal vein blood and the adrenaline solutions can be done in quite the same manner, viz. with the same velocity in one and same place of the vein; and thirdly the same blood sample was applied to both methods, the pupil and the segment.

Now some examples will be given in full and the whole results are condensed in Table II. 
Example VI.

24. I. 1924. Cat 28. ô. 3 kilos.

\begin{tabular}{|c|c|c|c|c|c|c|c|}
\hline Tine & 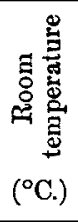 & 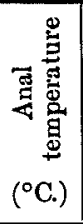 & 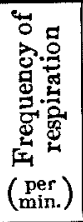 & 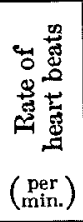 & 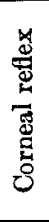 & 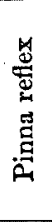 & Experimental processes \\
\hline $10: 36$ A.Mr. & 10.0 & 36.0 & 42 & 240 & 世 & $H$ & $\begin{array}{l}\text { Etherized and fastend. Put can- } \\
\text { nulae into trachea and r. ex- } \\
\text { ternal jugular vein, and obtain- } \\
\text { ed } S .0 \text { c.c. blood from jugular } \\
\text { rein through the cannula. }\end{array}$ \\
\hline $\begin{array}{l}11: 14 \\
11: 15-\end{array}$ & 12.5 & 36.0 & 26 & 210 & H & H & $\begin{array}{l}\text { Made cava pocket, a. coeliaca } \\
\text { and a. mes. sup. ligated. }\end{array}$ \\
\hline $11: 50$ & 13.5 & $(36.0)$ & 42 & 192 & $H$ & $H$ & \\
\hline $\begin{array}{l}\text { 12:10 P.M. } \\
12: 11\end{array}$ & 14.5 & $(35.0)$ & 48 & 192 & $H$ & $H$ & $\begin{array}{l}\text { Collected c. p. specimen I, after } \\
\text { discarded } 0.6 \text { c.c. of cava blood. }\end{array}$ \\
\hline $12: 19$ & 15.0 & $(35.0)$ & 60 & 186 & + & + & \\
\hline $\begin{array}{l}12: 27 \\
12: 28\end{array}$ & 15.0 & $(35.0)$ & 60 & 192 & + & + & $\begin{array}{l}\text { Collected c. p. specimen II, after } \\
\text { discarded } 0.6 \text { c.c. of cara blood. }\end{array}$ \\
\hline 12:32 & 15.5 & $(35.0)$ & 60 & 240 & + & + & \\
\hline $\begin{array}{l}12: 40 \\
12: 42\end{array}$ & 16.0 & $(35.0)$ & 60 & 192 & + & + & $\begin{array}{l}\text { Collected c. p. specimen III, after } \\
\text { discarded } 0.7 \text { c.c. of cava blood. }\end{array}$ \\
\hline $12: 47$ & 16.0 & $(35.0)$ & 48 & 180 & + & + & \\
\hline $\begin{array}{r}12: 59 \\
1: 02\end{array}$ & 16.0 & $(35.0)$ & 54 & 186 & + & + & $\begin{array}{l}\text { Collected c. p. specimen IV, after } \\
\text { discarded } 0.4 \text { c.c. of cava blood. }\end{array}$ \\
\hline $1: 10$ & 16.0 & $(35.0)$ & 54 & 186 & + & + & \\
\hline $\begin{array}{l}1: 18 \\
1: 30\end{array}$ & 16.0 & $(35.0)$ & 60 & 192 & 1 & + & Final bleeding from abd. aorta. \\
\hline
\end{tabular}

Assay on denervated eye on Cat 38 ( $~ .2 .75$ kilos.). Left sup. cerv. gangl. had been excised 8 days before.

3:43 P.M. 4.12 grms. (1.5 grms. per kilo) urethane by stomach tube.

4:20 Fastend. Put cannulae into trachea and r. ext. jugular vein, and obtained 15 c.c. of indifferent blood from jugular vein.

\begin{tabular}{|c|c|c|c|c|c|c|c|c|}
\hline Time & $\begin{array}{l}\text { Quantity of c. p. } \\
\text { spec. (c.c.) or } \\
\text { quantity of adre- } \\
\text { naline hydro- } \\
\text { chloride solution } \\
\text { (c.c.) in a given } \\
\text { concentration } \\
\text { (total in } 3 \text { c.c.) } 8 \\
\end{array}$ & 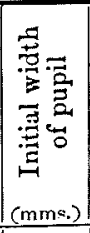 & 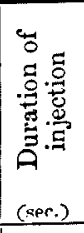 & 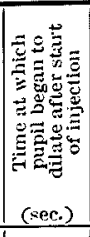 & 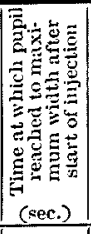 & 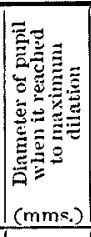 & 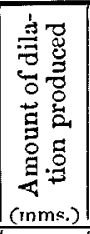 & Remarks \\
\hline $\begin{array}{l}\text { 5:11 P.Mr. } \\
\text { 5:14 }\end{array}$ & $\begin{array}{lll}1 / 1000,000 & 0.5 \\
1 / 1000,000 & 1.0\end{array}$ & $\begin{array}{l}5.0 \\
5.0\end{array}$ & $\begin{array}{l}8 \\
7\end{array}$ & $\begin{array}{l}20 \\
15\end{array}$ & $\begin{array}{l}26 \\
23\end{array}$ & $\begin{array}{l}5.25 \\
6.5\end{array}$ & $\left|\begin{array}{l}0.25- \\
1.5\end{array}\right|$ & Dilations \\
\hline
\end{tabular}

$\$$ Adrenaline blood solution which was injected for comparison : Ty rode's solution 3.0-1.0-2 $\alpha$, double Ty rod e's solution $\alpha$ c.c., indifferent blood from Cat No. 281 c.c., adrenaline hydrochloride solution $\alpha$ c.c. Cava pocket blood solution for injection : c. p. blood 1 c.c. and $\mathrm{T}$ y rode's solution 2 c.c. 


\begin{tabular}{|c|c|c|c|c|c|c|c|c|}
\hline Time & $\begin{array}{l}\text { Quantity of c. p. } \\
\text { spec. (c.c.) or } \\
\text { quantity of adre- } \\
\text { naline hydro- } \\
\text { chloride solution } \\
\text { (c.c.) in a given } \\
\text { concentration } \\
\text { (total in } 3 \text { c.c.) }\end{array}$ & 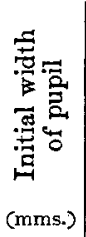 & 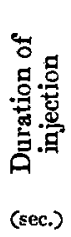 & 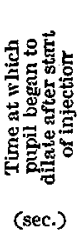 & 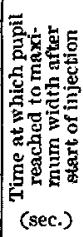 & 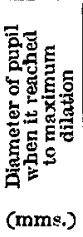 & 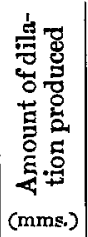 & Remarks $_{\text {S }}$ \\
\hline 5:19 P.M. & $1 / 200,000 \quad 0.1$ & 5.0 & 7 & 12 & 24 & 5.25 & 0.25 & Dilation slightly. \\
\hline $5: 24$ & 0.2 & 5.0 & 7 & 15 & 25 & 6.5 & 1.5 & \\
\hline $5: 29$ & 0.3 & 6.0 & 7 & 12 & 25 & 8.0 & 2.0 & \\
\hline $5: 34$ & 0.4 & 6.0 & 7 & 12 & 23 & $8.5+$ & $2 . \overline{5}+$ & \\
\hline $5: 39$ & 0.5 & 6.0 & 6 & 11 & 24 & 9.0 & 3.0 & \\
\hline $5: 48$ & 0.3 & 6.0 & 6 & 11 & 22 & $8.0+$ & $2.0+$ & \\
\hline $5: 53$ & $1 / 1,000,0001.0$ & $5.5+$ & $s$ & 13 & 20 & $6.75+$ & $1.25+$ & \\
\hline $5: 59$ & 0.5 & $5.5+$ & 8 & 15 & 23 & $5.75+$ & 0.25 & \\
\hline $6: 06$ & 1 c.c. & $5.0+$ & 8 & 15 & 26 & $5.5+$ & 0.5 & \\
\hline $6: 12$ & $1 / 1,000,0000.7$ & 5.0 & 8 & 14 & 24 & 5.5 & 0.5 & \\
\hline $6: 17$ & 1 c.c. & 5.0 & 8 & 15 & 26 & 5.75 & 0.75 & \\
\hline $6: 23$ & $1 / 1,000,0000.8$ & 5.0 & 8 & 12 & 23 & 6.0 & 1.0 & \\
\hline $6: 35$ & 1 c.c. & 4.5 & 7 & 11 & 23 & 5.25 & 0.75 & \\
\hline $6: 40$ & $1 / 1,000,0000.7$ & 4.5 & 7 & 12 & 22 & 5.0 & 0.5 & \\
\hline $6: 44$ & 1 c.c. & 5.0 & 7 & 12 & 25 & 6.0 & 1.0 & \\
\hline $6: 48$ & $1 / 1,000,0000.8$ & 4.5 & 7 & 15 & 19 & 5.75 & 1.25 & \\
\hline & 0.4 & $4.0-$ & 7 & & & & & No reaction!! \\
\hline 6 & 0.5 & 4.0 & 6 & 14 & 18 & $4.25-$ & 0.25 & Reaction slightly. \\
\hline $6:$ & 0.6 & 4.0 & 7 & 13 & 17 & $4.25+$ & $0.25+$ & \\
\hline $7:$ & 0.7 & 3.5 & 8 & 15 & 19 & 4.0 & 0.5 & \\
\hline & 0.8 & 3.25 & 8 & 16 & 19 & 4.25 & 1.0 & \\
\hline $7: 10$ & $1 / 200,000$ & 3.25 & 7 & 13 & & & & Dilation quite slightly. \\
\hline & 0.3 & 3.0 & 7 & 10 & 18 & $5.5-$ & $2.5-$ & \\
\hline $7: 1$ & 0.2 & 35 & 7 & 11 & 17 & $4.5+$ & $1.0+$ & \\
\hline
\end{tabular}

Epinephrine concentration and output determined by paradoxical eye reaction :

\begin{tabular}{|c|c|c|c|c|c|c|}
\hline \multirow{2}{*}{$\begin{array}{c}\text { No. of } \\
\text { cava } \\
\text { pocket } \\
\text { specimen }\end{array}$} & \multirow{2}{*}{$\begin{array}{l}\text { Blood } \\
\text { flow per } \\
\text { minute } \\
\text { (c.c.) }\end{array}$} & \multirow{2}{*}{$\begin{array}{l}\text { Quantity } \\
\text { of } \\
\text { specimen } \\
\text { used for } \\
\text { an assay } \\
\text { (c.c.) }\end{array}$} & \multirow{2}{*}{$\begin{array}{l}\text { Amount } \\
\text { of pupil } \\
\text { dilation } \\
\text { (mm.) }\end{array}$} & \multirow{2}{*}{$\begin{array}{l}\text { Quantity of } \\
\text { adrenaline } \\
\text { hydrochloride } \\
\text { which caused } \\
\text { same amount } \\
\text { of dilation } \\
\text { (mgrm.) }\end{array}$} & \multicolumn{2}{|c|}{$\begin{array}{l}\text { Epinephrine output } \\
\text { per minute } \\
\text { (mgrm.) }\end{array}$} \\
\hline & & & & & per animal & per kilo \\
\hline I & 1.5 & 1.0 & 0.5 & 0.00 & 0.00105 & 0.00035 \\
\hline II & 1.3 & 1.0 & 0.75 & 0.00075 & 0.00097 & 0.00032 \\
\hline III & 1.3 & 1.0 & 0.75 & 0.00075 & 0.00097 & 0.00032 \\
\hline IV & 1.0 & 1.0 & 1.0 & 0.00077 & 0.00077 & 0.00026 \\
\hline
\end{tabular}

Epinephrine output determined by rabbit intestine segment :

$\S$ See foot-note on p. 385. 


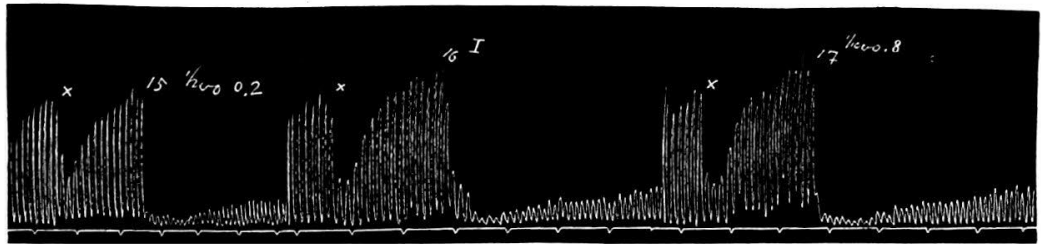

Fig. 2. a.§ At 15 and 17 adrenaline blood solutions which contained 0.2 c.c. of adrenaline hydrochloride solution in the strength of $1: 200,000$ and 0.8 c.c. of adrenaline hydrochloride solution in $1: 1,000,000$ per 0.5 c.c. were respectively applied. At 16 I cava pocket specimen solution was applied.

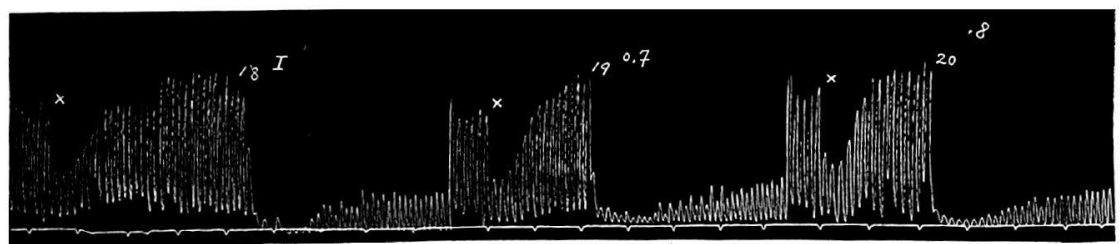

Fig. 2. b. At 18 I cava pocket specimen solution was applied. At 19 and 20 adrenaline blood solutions which contained 0.7 c.c. and 0.8 c.c. of adrenaline hydrochloride solution in the strength of $1: 1,000,000$ per 0.5 c.c. were respectively applied.

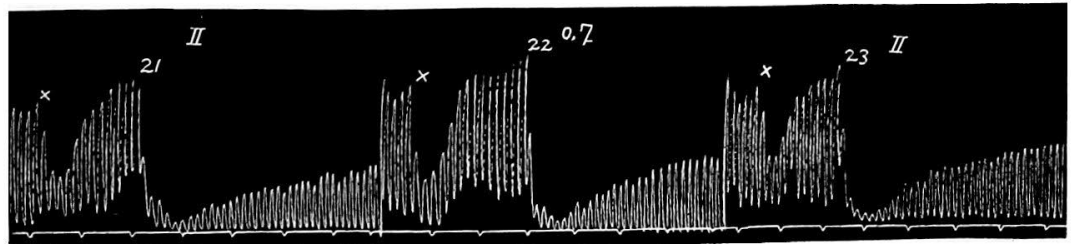

Fig. 2. c. At 21 and 23 II cara pocket specimen solution was applied. At 22 adrenaline blood solution which contained 0.7 c.c. of adrenaline hydrochloride solution in the strength of $1: 1,000,000$ per 0.5 c.c. was applied.

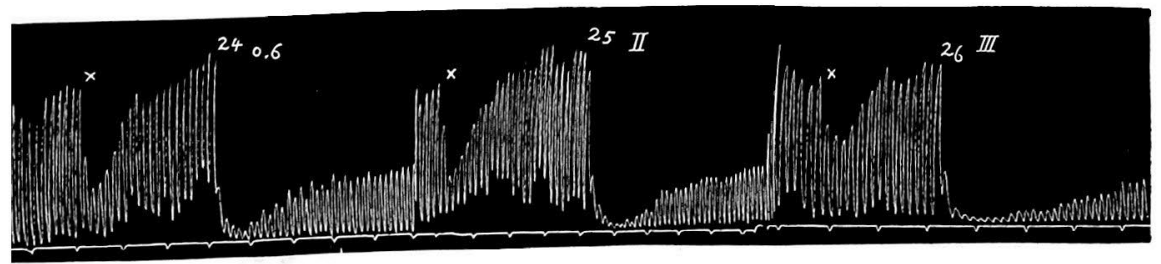

Fig. 2. d. At 24 adrenaline blood solution which contained 0.6 c.c. of adrenaline hydrochloride solution in the strength of $1: 1,000,000$ per 0.5 c.c. At 25 and 26 II and III cava pocket specimen solutions were respectively applied.

$\S$ See foot-note on p. 374 . 


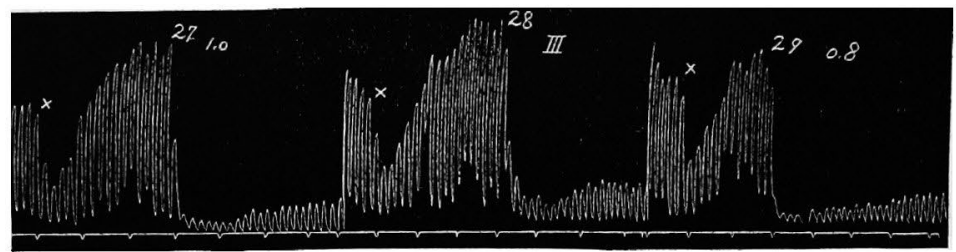

Fig. 2. e. At 27 and 29 adrenaline blood solutions which contained 1.0 c.c. and 0.8 c.c. of adrenaline hydrochloride solution in the strength of $1: 1,000,000$ per 0.5 c.c. were respectively applied. At 28 III cava pocket specimen solution was applied.

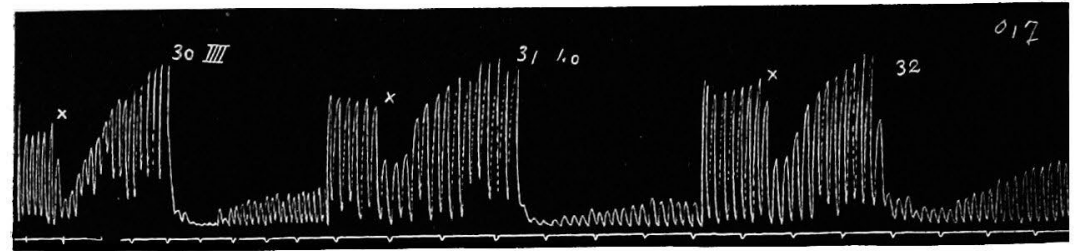

Fig. 2. f. At 30 IV cava pocket specimen solution was applied. At 31 and 32 adrenaline blood solutions which contained 1 c.c. and 0.7 c.c. of adrenaline hydrochloride solution in the strength of $1: 1,000,000$ per 0.5 c.c. were respectively applied.

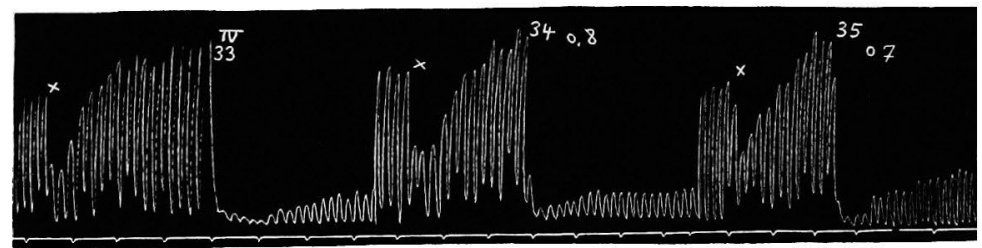

Fig. 2. g. At 33 IV cava pocket specimen solution was applied. At 34 and 35 adrenaline blood solutions which contained 0.8 c.c. and 0.7 c.c. of adrenaline hydrochloride solution in the strength of $1: 1,000,000$ per 0.5 c.c. were respectively applied.

To sum up :

Sample I: Weaker than 0.2 c.c. of $1: 200,000$ per 0.5 c.c.; slightly weaker than 0.8 c.c. of $1: 1,000,000$ per 0.5 c.c.; slightly stronger than 0.7 c.c. of $1: 1,000,000$ per 0.5 c.c. I was taken at 0.0015 mgrm. per 1 c.c.

Sample II : Weaker than 0.8 c.c. of $1: 1,000,000$ per 0.5 c.c.; almost the same with 0.7 c.c. of $1: 1,000,000$ per 0.5 c.c. : stronger than 0.6 c.c. of $1: 1,000,000$ per 0.5 c.c. ; weaker than III. II was assayed as $0.0014 \mathrm{mgrm}$. per 1 c.c.

Sample III : Stronger than II; weaker than 1 c.c. of $1: 1,000,000$ per 0.5 c.c.; weaker than 0.8 c.c. of $1: 1,000,000$ per 0.5 c.c. III was taken at 0.0015 mgrm. per 1 c.c.

Sample IV : Slightly stronger than 0.8 c.c. of $1: 1,000,000$ per 0.5 c.c.; weaker than 1.0 c.c. of $1: 1,000,000$ per 0.5 c.c. ; stronger than 0.7 c.c. of $1: 1,000,000$ per 0.5 c.c. IV was taken at $0.0018 \mathrm{mgrm}$. per 1 c.c. 
Epinephrine concentration and output determined by rabbit intestine segment :

\begin{tabular}{|c|c|c|c|c|c|c|c|}
\hline \multirow{3}{*}{$\begin{array}{c}\text { No. of } \\
\text { cava } \\
\text { pocket } \\
\text { specimen }\end{array}$} & \multicolumn{4}{|c|}{ Blood flow (c.c.) } & \multicolumn{3}{|c|}{ Epinephrine output (mgrm.) } \\
\hline & \multirow{2}{*}{ Quantity } & \multirow{2}{*}{$\begin{array}{c}\text { Duration } \\
\text { of } \\
\text { collection } \\
\text { (sec.) }\end{array}$} & \multicolumn{2}{|c|}{$\begin{array}{l}\text { Quantity } \\
\text { per minute }\end{array}$} & \multirow{2}{*}{$\begin{array}{l}\text { Quantity } \\
\text { contained } \\
\text { in } 1 \text { c.c. }\end{array}$} & \multicolumn{2}{|c|}{$\begin{array}{c}\text { Output } \\
\text { per minute }\end{array}$} \\
\hline & & & $\begin{array}{c}\text { per } \\
\text { animal }\end{array}$ & $\begin{array}{l}\text { per } \\
\text { kilo }\end{array}$ & & $\underset{\text { animal }}{\text { per }}$ & $\begin{array}{l}\text { per } \\
\text { kilo }\end{array}$ \\
\hline I & 3.1 & 120 & 1.5 & 0.5 & 0.0015 & 0.00225 & 0.00075 \\
\hline II & 3.3 & 150 & 1.3 & 0.43 & 0.0014 & 0.00182 & 0.00061 \\
\hline III & 3.9 & 180 & 1.3 & 0.43 & 0.0015 & 0.00195 & 0.00065 \\
\hline IV & 2.5 & 150 & 1.0 & 0.33 & 0.0018 & 0.0018 & 0.0006 \\
\hline
\end{tabular}

Ratio of the two assays.

\begin{tabular}{c|c|c|c}
\hline \multirow{2}{*}{$\begin{array}{c}\text { No. of } \\
\text { specimen }\end{array}$} & \multicolumn{2}{|c|}{ Epinephrine content in 1 c.c. (mgrm.) } & \multicolumn{1}{c}{$\begin{array}{c}\text { Ratio } \\
\text { (Eye : Intestine) }\end{array}$} \\
\cline { 2 - 4 } & pupil & intestine & $1: 2.1$ \\
I & $\mathbf{0 . 0 0 0 7}$ & 0.0015 & $1: 1.8$ \\
II & $\mathbf{0 . 0 0 0 7 5}$ & 0.0014 & $1: 2.0$ \\
III & $\mathbf{0 . 0 0 0 7 5}$ & 0.0015 & $1: 2.3$ \\
IV & $\mathbf{0 . 0 0 0 7 7}$ & 0.0018 &
\end{tabular}

Example VII.

25. III. 1924. Cat 35. ․ 2.7 kilos.

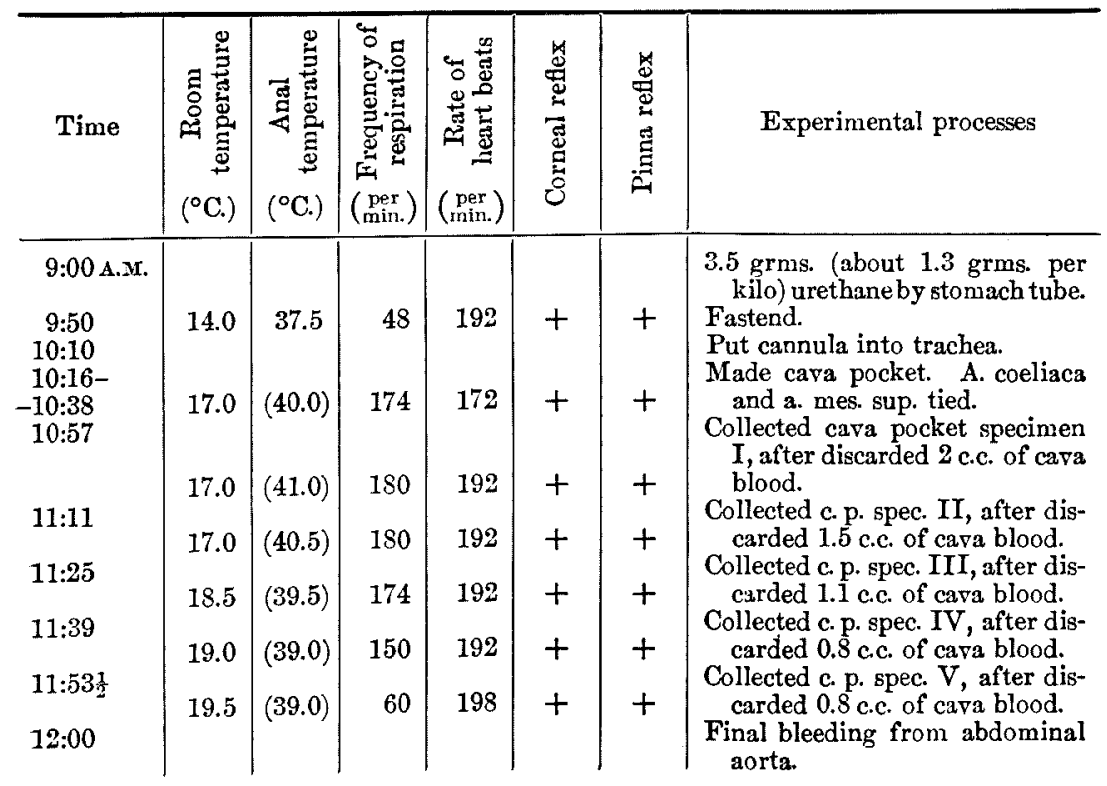


Epinephrine content of cava pocket specimens were estimated by means of the denervated eye of Cat No. 45.

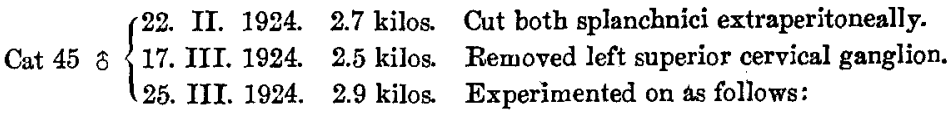

0:35 P.M. 3.7 grms. (1.3 grms. per kilo) urethane by stomach tube.

2:20 Put cannulae into trachea and r. external jugular vein after fastend.

Anaesthesia light, cat snarls.

2:37 1.14 grms. (0.4 grm. per kilo) urethane subcutaneously.

\begin{tabular}{|c|c|c|c|c|c|c|c|}
\hline$\left(\begin{array}{c}\text { hour : } \\
\text { min. }\end{array}\right)$ & $\begin{array}{c}\text { Quantity of cava } \\
\text { pocket specimen } \\
\text { (c.c.) and quantity } \\
\text { of adrenaline hydro- } \\
\text { chloride solution } \\
\text { (c.c.) in a given } \\
\text { concentration* }\end{array}$ & 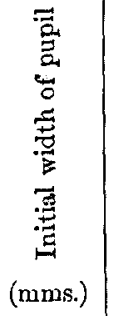 & 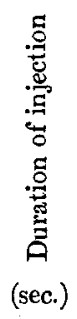 & 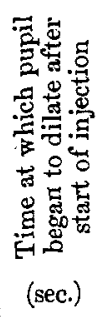 & 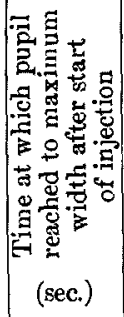 & 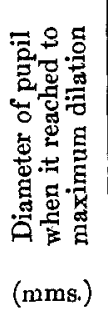 & 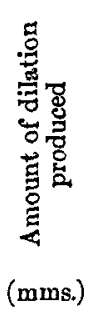 \\
\hline 3:00 P.M. & \multicolumn{3}{|c|}{ Both pupils thread like snall. } & & & \multirow{18}{*}{$\begin{array}{l}6.5 \\
3.5+ \\
3.0- \\
3.0- \\
4.0+ \\
6.5 \\
3.0 \\
4.5- \\
3.0 \\
3.0 \\
1.5+ \\
4.0 \\
3.5 \\
4.0 \\
4.5- \\
6.5 \\
6.5-\end{array}$} & \multirow{18}{*}{$\begin{array}{l}5.5 \\
2.5+ \\
2.0- \\
2.0- \\
3.0+ \\
5.5 \\
2.0 \\
3.5- \\
2.0 \\
2.0 \\
0.5+ \\
3.0 \\
2.5 \\
3.0 \\
3.0 \\
5.0+ \\
5.5-\end{array}$} \\
\hline $3: 04$ & ]$/ 500,000 \quad 0.3$ & 1.0 & 9 & 11 & 27 & & \\
\hline & " $\quad 0.2$ & 1.0 & 10 & 11 & $2 S$ & & \\
\hline & 0.1 & 1.0 & 10 & 14 & 30 & & \\
\hline 3: & 0.1 & 1.0 & 8 & 10 & 22 & & \\
\hline & 0.2 & 1.0 & 9 & 10 & 22 & & \\
\hline 3: & 0.3 & 1.0 & 10 & 10 & 22 & & \\
\hline $3:$ & 0.1 & 1.0 & 9 & 10 & 21 & & \\
\hline & 0.2 & 1.0 & 9 & 10 & 22 & & \\
\hline $3: 45$ & 1.0 & 1.0 & 10 & 10 & 22 & & \\
\hline $3: 49$ & $1 / 500,000 \quad 0.1$ & 1.0 & 9 & 10 & 22 & & \\
\hline $3: 5$ & 0.05 & 1.0 & 9 & 12 & 20 & & \\
\hline $4: 02$ & 1.0 & 1.0 & 10 & 10 & 19 & & \\
\hline $4: 0$ & $1 / 500,000 \quad 0.15$ & 1.0 & 9 & 9 & 22 & & \\
\hline $4: 1$ & II & 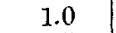 & 9 & 9 & 20 & & \\
\hline $4: 14$ & 0.2 & $1.5-$ & 9 & 9 & 22 & & \\
\hline 41 & III & 1.5 & 9 & 6 & 21 & & \\
\hline & 0.3 & $1.0+1$ & 9 & 9 & 23 & & \\
\hline $4: 30$ & \multicolumn{6}{|c|}{ Obtained some quantity of blood from femoral artery. } & \\
\hline $4: 51$ & $1 / 500,000 \quad 0.3$ & 1.5 & 9 & 9 & 27 & $7.0-$ & $5.5-$ \\
\hline & $\mathrm{V} \quad 1.0$ & 1.5 & 9 & $\begin{array}{l}9 \\
9\end{array}$ & $\begin{array}{l}22 \\
26\end{array}$ & $\begin{array}{l}7.0- \\
5.5\end{array}$ & $\begin{array}{l}5.5- \\
4.0\end{array}$ \\
\hline $4: 58$ & $1 / 500,000 \quad 0.25$ & 1.5 & 9 & 9 & & & \\
\hline
\end{tabular}

* Adrenaline blood solution which was injected for comparison: Ty rod e's solution 2.5-1.0-2 $\alpha$, double T y rode's solution $\alpha$ c.c., indifferent blood from Cat No. 351.0 c.c., adrenaline hydrochloride solution $\propto$ c.c. Cava pocket blood solution for injection: C. p. blood 1.0 c.c. and Ty rode's solution 1.5 c.c.

To sum up :

Sample I: Weaker than 0.2 c.c. of $1: 500,000$; stronger than 0.05 c.c. of $1: 500,000$ and as strong as 0.1 c.c. of $1: 500,000$. It was assayed at $0.0002 \mathrm{mgrm}$. in 1 c.c.

Sample II : Stronger than 0.05 c.c. and 0.15 c.c. of $1: 500,000$; as strong as 0.2 c.c. of $1: 500,000$. It was assayed at $0.0004 \mathrm{mgrm}$. in 1 c.c.

Sample III : Stronger than 0.2c.c. of $1: 500,000$; almost as strong as 0.3 c.c. of $1: 500-$ 000 . It was taken as $0.0006 \mathrm{mgrm}$. in 1 c.c. 
Sample V: Stronger than 0.25 c.c. of $1: 500,000$; almost as strong as 0.3 c.c. of $1: 500$ 000. It was taken as $0.0006 \mathrm{mgrm}$. in 1 c.c.

Of the remaining portion of each cava pocket specimen epinephrine content was estimated by means of the rabbit intestine strip.

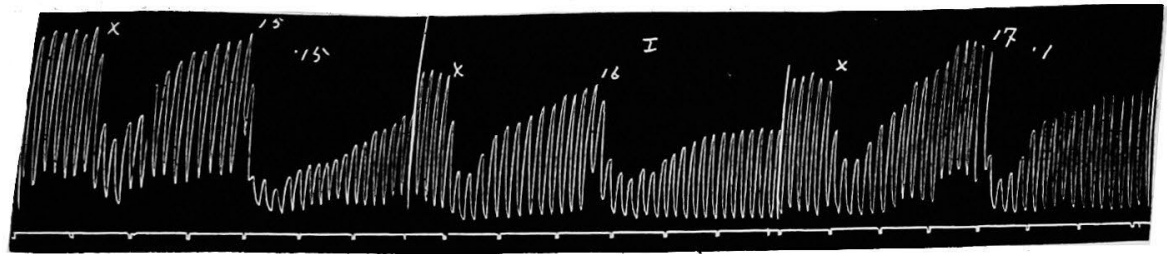

Fig. 3. a. $\S$ At 15 and 17 adrenaline blood solutions which contained 0.15 c.c. and 0.1 c.c. of adrenaline hydrochloride solution of $1: 500,000$ per 0.5 c.c. were respectively applied. At 16 I c. p. specimen solution was applied.

I: Weaker than 0.15 c.c. of $1: 500,000$; decidedly stronger than 0.1 c.c. of $1: 500,000$.

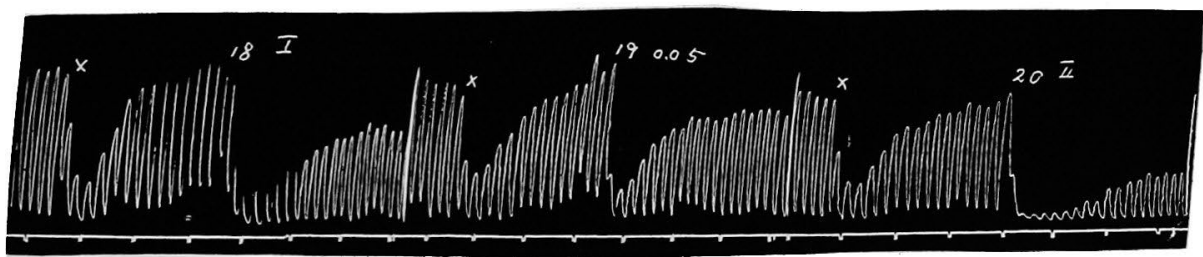

Fig. 3. b. At 18 and $20 \mathrm{I}$ and II c.p. specimen solutions were applied, at 19 adrenaline blood solution which contained 0.05 c.c. of adrenaline hydrochloride solution of $1: 500,000$ per 0.5 c.c. was applied.

I : Decidedly stronger than 0.05 c.c. and 0.1 c.c. of $1: 500,000$.

II : Decidedly stronger than 0.05 c.c. and 0.2 c.c. (Obs. 21 ) of $1: 500,000$.

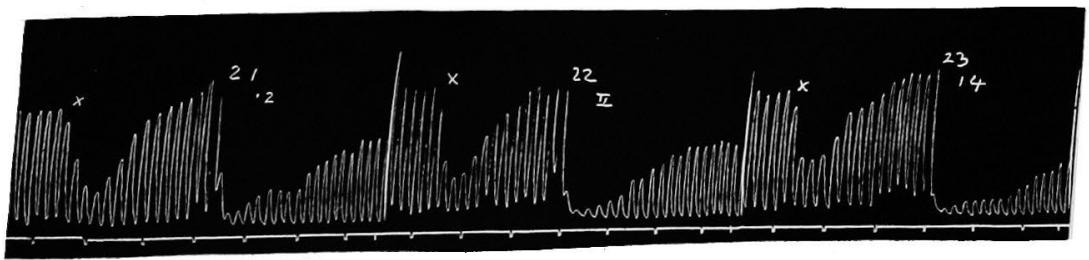

Fig. 3. c. At 21 and 23 adrenaline blood solutions which contained 0.2 c.c. and 0.4 c.c. of adrenaline hydrochloride solution of $1: 500,000$ per 0.5 c.c. were respectively applied. At 22 II. c. p. specimen solution was applied.

II : Stronger than 0.2 c.c. of $1: 500,000$; weaker than 0.4 c.c. of $1: 500,000$. Weaker than 0.3 c.c. of $1: 500,000$ (Obs. 24 ).

- $\S$ See foot-note on p. 374 . 


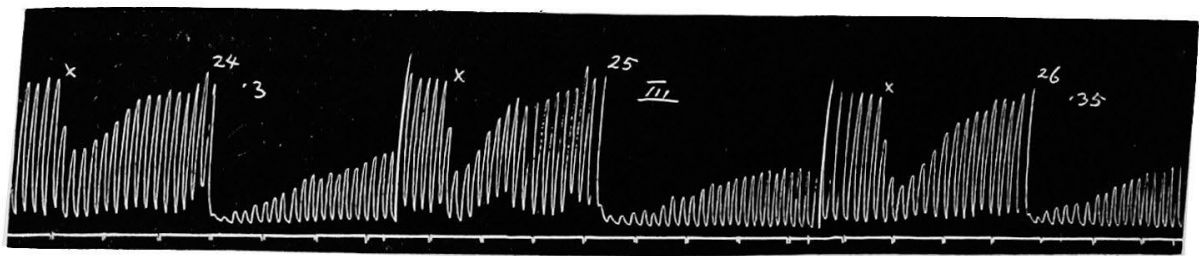

Fig. 3. d. At 24 and 26 adrenaline blood solutions which contained 0.3 c.c. and 0.35 c.c. of adrenaline hydrochloride solution of $1: 500,000$ per 0.5 c.c. were respectively applied. At 25 III. c.p. specimen solution was applied.

III : Stronger than 0.3 c.c. of $1: 500,000$; a little weaker than 0.35 c.c. of $1: 500,000$; almost as strong as 0.35 c.c. (obs. 27) of $1: 500,000$.

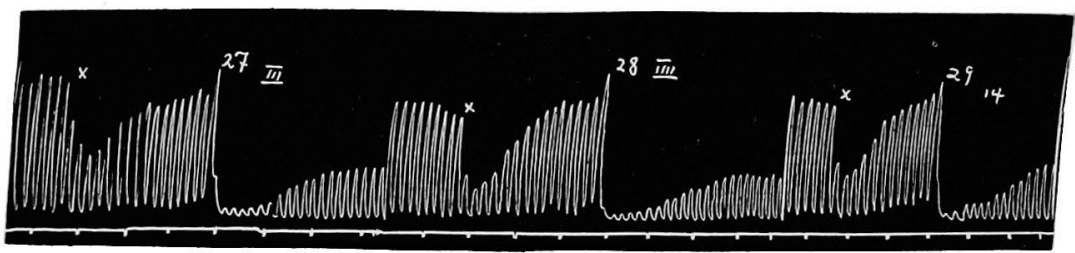

Fig. 3. e. At 27 and 28 III and IV c.p. specimen solutions were respectively applied. At 29 adrenaline blood solution which contained 0.4 c.c. of adrenaline hydrochloride solution of $1: 500,000$ per 0.5 c.c. was applied.

IV : Stronger than III; almost as strong as 0.4 c.c. of $1: 500,000$.

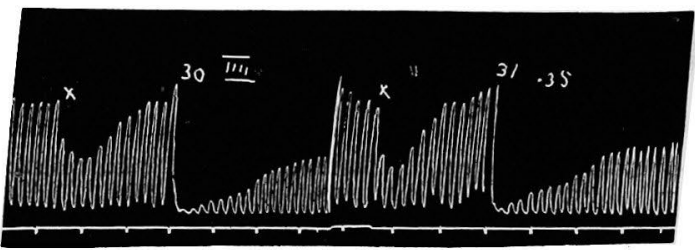

Fig. 3. f. At 30 IV c. p. specimen solution was applied; at 31 adrenaline blood solution which contained 0.35 c.c. of adrenaline hydrochloride solution of $1: 500,000$ per 0.5 c.c. was applied.

IV : Stronger than 0.35 c.c. of $1: 500,000$; almost as strong as 0.4 c.c. of $1: 500,000$ (Obs. 29).

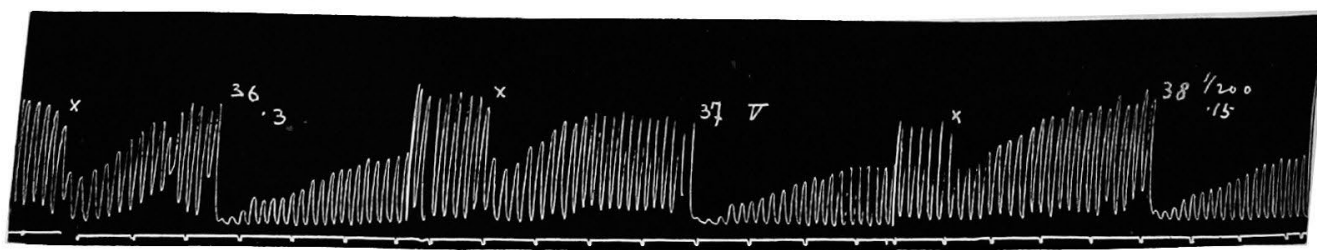

Fig. 3. g. At 36 adrenaline blood solution which contained 0.3 c.c. of adrenaline hydrochloride solution of $1: 500,000$ per 0.5 c.c. was applied. At $37 \mathrm{~V}$ c.p. specimen solution was applied. At 38 adrenaline blood solution which contained 0.15 c.c. of $1: 200,000$ adrenaline hydrochloride solution per 0.5 c.c. was applied.

V : Stronger than 0.3 c.c. of $1: 500,000$; almost as strong as 0.15 c.c. of $1: 200,000$. 


\section{To sum up :}

Sample I : Stronger than 0.05 c.c. and 0.1 c.c. of $1: 500,000$ per 0.5 c.c. ; weaker than 0.15 c.c. of $1: 500,000$ per 0.5 c.c. I was taken as 0.0005 mgrm. in 1 c.c.

Sample II: Stronger than 0.05 c.c. and 0.2 c.c. of $1: 500,000$ per 0.5 c.c.; weaker than 0.4 c.c. and 0.3 c.c. of $1: 500,000$ per 0.5 c.c. II was taken as 0.0009 mgrm. in 1 c.c.

Sample III : Stronger than 0.3 c.c. of $1: 500,000$ per 0.5 c.c.; weaker than IV; and almost as strong as 0.35 c.c. of $1: 500,000$ per 0.5 c.c. III was assayed at $0.0014 \mathrm{mgrm}$. in 1 c.c.

Sample IV : Stronger than III; stronger than 0.35 c.c. of $1: 500,000$ per 0.5 c.c.; almost as strong as 0.4 c.c. of $1: 500,000$ per 0.5 c.c. IV was assayed at $0.0016 \mathrm{mgrm}$. in 1 c.c.

Sample V : Stronger than 0.3 c.c. per 0.5 c.c.; as strong as 0.15 c.c. of $1: 200,000$ per 0.5 c.c. $V$ was assayed at $0.0015 \mathrm{mgrm}$. in 1 c.c.

These determinations were further verified by some other tracings not reproduced.

Ratio of epinephrine contents estimated by two methods :

\begin{tabular}{c|c|c|c}
\hline \multirow{2}{*}{$\begin{array}{c}\text { No. of c.p. } \\
\text { specimen }\end{array}$} & \multicolumn{2}{|c|}{ Epinephrine content in 1 c.c. (mgrm.) } & $\begin{array}{c}\text { Ratio } \\
\text { (Eye : Intestine) }\end{array}$ \\
\cline { 2 - 4 } & denervated eye & intestine strip & 1 :2.5 \\
II & 0.0002 & 0.0005 & $1: 2.2$ \\
III & 0.0004 & 0.0009 & $1: 2.3$ \\
IIV & 0.0006 & 0.0014 & - \\
V & 0.0006 & 0.0016 & $1: 2.5$
\end{tabular}

EXAMPLE VIII.

19. II. 1924. Cat 33. ô. 3.8 kilos.

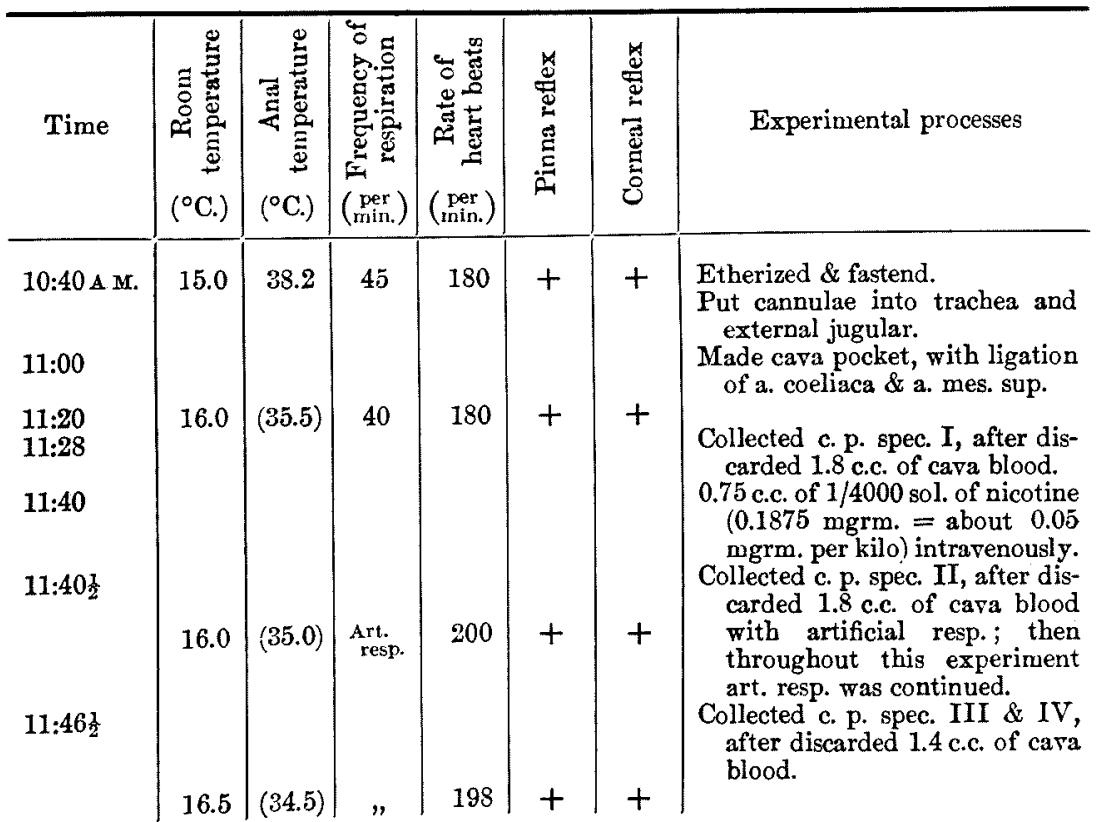




\begin{tabular}{|c|c|c|c|c|c|c|c|}
\hline Time & 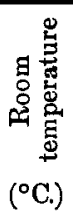 & 㞼怘 & 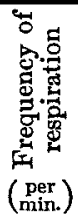 & 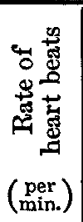 & 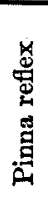 & 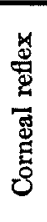 & Experimental processes \\
\hline 12:01 P.M. & 17.0 & $(34.5)$ & Art. & 198 & + & 1 & Collected c. p. spec. V, after dis- \\
\hline $\begin{array}{l}12: 15 \\
12: 25\end{array}$ & 17.5 & $(36.0)$ & , & 180 & + & + & $\begin{array}{l}\text { Collected c. p. spec. VI, after dis- } \\
\text { carded } 1.0 \text { c.c. of cava blood. } \\
\text { Final bleeding from abd. aorta. }\end{array}$ \\
\hline
\end{tabular}

Assay on denervated eye on Cat No. 43. ( .1 .2 kilos. L. sup. cerv. ggl. had been excised before 20 days.)

2:00 p.m. 1.4 grms. per kilo of urethane by stomach tube.

2:53 Fastend.

3:04 Put cannula into r. ext. jugular vein.

\begin{tabular}{|c|c|c|c|c|c|c|c|c|}
\hline Time & $\begin{array}{l}\text { Quantity of } \\
\text { pocket speci } \\
\text { (c.c.) or quant } \\
\text { adrenaline h } \\
\text { chloride solt } \\
\text { (c.c.) in a gi } \\
\text { concentrat } \\
\text { (total in } 2.5\end{array}$ & $\begin{array}{l}\text { cava } \\
\text { imen } \\
\text { tity of } \\
\text { ydro- } \\
\text { ution } \\
\text { iven } \\
\text { ion } \\
\text { c.c. } \$\end{array}$ & 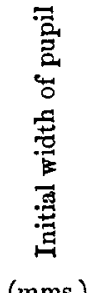 & 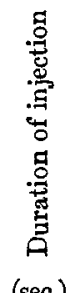 & 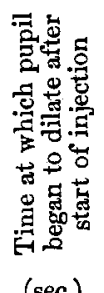 & 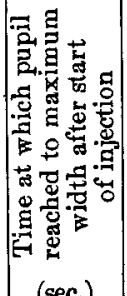 & 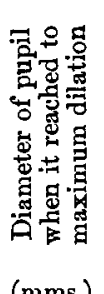 & 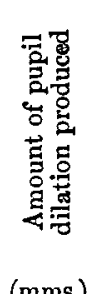 \\
\hline $\begin{array}{l}3: 12 \text { P.M. } \\
3: 14 \\
3: 17 \\
3: 20 \\
3: 26 \\
3: 30 \\
3: 34 \\
3: 37 \\
3: 39 \\
3: 42 \\
3: 45 \\
3: 48 \\
3: 51 \\
3: 55 \\
4: 01 \\
4: 05\end{array}$ & $\begin{array}{c}1 / 200,000 \\
" \\
" \\
" \\
\text { I } \\
1 / 200,000 \\
" \\
" \\
\text { I } \\
1 / 200,000 \\
\text { I" } \\
1 / 200,000 \\
"\end{array}$ & $\begin{array}{l}0.5 \\
0.5 \\
0.4 \\
0.4 \\
0.2 \\
1.0 \\
0.4 \\
0.4 \\
0.3 \\
0.3 \\
0.5 \\
0.2 \\
0.5 \\
1.0 \\
0.4 \\
0.5\end{array}$ & $\begin{array}{l}1.0 \\
1.0 \\
1.0 \\
1.0 \\
1.0 \\
1.0 \\
1.0 \\
1.0 \\
1.0 \\
1.0 \\
1.0 \\
1.0 \\
1.0 \\
1.0 \\
1.5 \\
1.5\end{array}$ & $\begin{array}{l}7 \\
7 \\
7 \\
6 \\
7 \\
5 \\
5 \\
6 \\
7 \\
7 \\
6 \\
7 \\
6 \\
6 \\
7 \\
7\end{array}$ & $\begin{array}{r}10 \\
8 \\
8 \\
9 \\
10 \\
10 \\
8 \\
9 \\
11 \\
11 \\
10 \\
11 \\
9 \\
10 \\
8 \\
8\end{array}$ & $\begin{array}{l}23 \\
21 \\
20 \\
23 \\
18 \\
20 \\
21 \\
23 \\
20 \\
19 \\
20 \\
17 \\
23 \\
24 \\
23 \\
25\end{array}$ & $\begin{array}{l}4.0+ \\
4.0+ \\
4.0- \\
4.0- \\
2.0+ \\
4.0 \\
4.0- \\
4.0- \\
3.0+ \\
3.5- \\
3.0 \\
3.0- \\
4.5+ \\
6.0 \\
6.0- \\
6.5-\end{array}$ & $\begin{array}{l}3.0+ \\
3.0+ \\
3.0- \\
3.0- \\
1.0+ \\
3.0 \\
3.0- \\
3.0- \\
2.0+ \\
2.5- \\
.0- \\
2.0- \\
3.5+ \\
5.0 \\
4.5- \\
5.0-\end{array}$ \\
\hline $\begin{array}{l}4: 10 \\
4: 47 \\
4: 51 \\
4: 55\end{array}$ & $\begin{array}{c}\text { c. of blood } \\
1 / 40,000 \\
\text { II } \\
1 / 200,000\end{array}$ & $\begin{array}{l}\text { from } f \\
0.15 \\
1.0 \\
0.5\end{array}$ & $\begin{array}{l}\text { oral a } \\
1.5 \\
2.0 \\
3.5\end{array}$ & $\begin{array}{l}7 \\
8 \\
7\end{array}$ & $\begin{array}{l}8 \\
8 \\
8.5\end{array}$ & $\begin{array}{l}24 \\
19 \\
20\end{array}$ & $\begin{array}{l}7.0 \\
8.0+\end{array}$ & $\begin{array}{l}7.0 \\
5.0 \\
4.5+\end{array}$ \\
\hline
\end{tabular}

$\S$ Adrenaline blood solution which was injected for comparison: Ty rode's solution 2.5-1.0-2 $\alpha$, double T y rod e's solution $\alpha$ c.c., indifferent blood from Cat No. 33 1.0 c.c., adrenaline hydrochloride solution $\alpha$ c.c. Cava pocket blood solution for injection: C. p. blood 1.0 c.c. and Ty rod e's solution 1.5 c.c. 


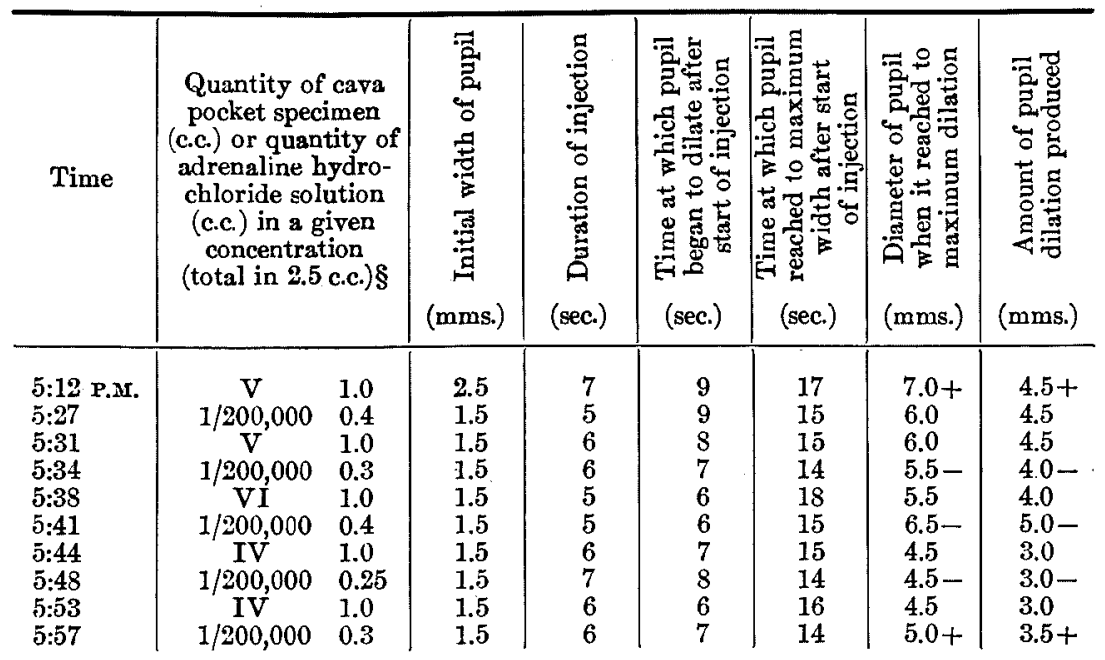

Epinephrine output determined by paradoxical eye reaction of cat :

\begin{tabular}{|c|c|c|c|c|c|}
\hline \multirow{2}{*}{$\begin{array}{c}\text { No. of } \\
\text { cava pocket } \\
\text { specimen }\end{array}$} & \multirow{2}{*}{$\begin{array}{c}\text { Time of } \\
\text { collection } \\
\text { (min.) }\end{array}$} & \multirow{2}{*}{$\begin{array}{l}\text { Quantity of } \\
\text { specimen } \\
\text { used for } \\
\text { one assay } \\
\text { (c.c.) }\end{array}$} & \multirow{2}{*}{$\begin{array}{c}\text { Quantity of } \\
\text { adrenaline } \\
\text { hydrochloride } \\
\text { which caused } \\
\text { same amount } \\
\text { of dilation } \\
\text { (mgrm.) }\end{array}$} & \multicolumn{2}{|c|}{$\begin{array}{l}\text { Epinephrine output } \\
\text { per minute }\end{array}$} \\
\hline & & & & $\begin{array}{l}\text { per animal } \\
\text { (mgrm.) }\end{array}$ & $\begin{array}{l}\text { per kilo } \\
\text { (mgrm.) }\end{array}$ \\
\hline I & before 48 & 1.0 & 0.00225 & 0.00562 & 0.00148 \\
\hline
\end{tabular}

About $0.05 \mathrm{mgrm}$. nicotine intravenously.

\begin{tabular}{l|cc|c|l|l|l} 
II & after & $\frac{1}{2}$ & 1.0 & 0.00325 & 0.0073 & 0.00205 \\
IV & $n$ & 8 & 1.0 & 0.00125 & 0.0025 & 0.00065 \\
V & $"$ & 21 & 1.0 & 0.002 & 0.0032 & 0.00084 \\
VI & $\#$ & 35 & 1.0 & 0.00174 & 0.00262 & 0.00069
\end{tabular}

Epinephrine output determined by rabbit intestine segment :

\begin{tabular}{c|c|c|c|c|c|c|c}
\hline \multirow{2}{*}{$\begin{array}{c}\text { No. of } \\
\text { cava } \\
\text { pocket } \\
\text { specimen }\end{array}$} & Quantity & $\begin{array}{c}\text { Buration } \\
\text { of } \\
\text { collection } \\
\text { (sec.) }\end{array}$ & \begin{tabular}{c} 
Quantity per minute \\
\cline { 5 - 7 }
\end{tabular} & $\begin{array}{c}\text { per } \\
\text { animal }\end{array}$ & $\begin{array}{c}\text { per } \\
\text { kilo }\end{array}$ & $\begin{array}{c}\text { Euantity } \\
\text { contained } \\
\text { in 1 c.c. }\end{array}$ & \multicolumn{2}{|c|}{$\begin{array}{c}\text { Output per minute } \\
\text { animal }\end{array}$} & $\begin{array}{c}\text { per } \\
\text { kilo }\end{array}$ \\
\hline & & 90 & 2.5 & 0.66 & 0.0035 & 0.00875 & 0.0023 \\
I & 3.8 & 90 & 2.4 & 0.63 & 0.0065 & 0.0156 & 0.0041 \\
II & 3.6 & 90 & 2.0 & 0.52 & 0.0025 & 0.005 & 0.00131 \\
IV & 3.0 & 90 & 1.6 & 0.42 & 0.004 & 0.0064 & 0.00168 \\
V & 4.0 & 150 & 1.5 & 0.40 & 0.004 & 0.006 & 0.00157 \\
VI & 2.3 & 90 & 1.5 &
\end{tabular}

$\S$ See the foot note on p. 394. 


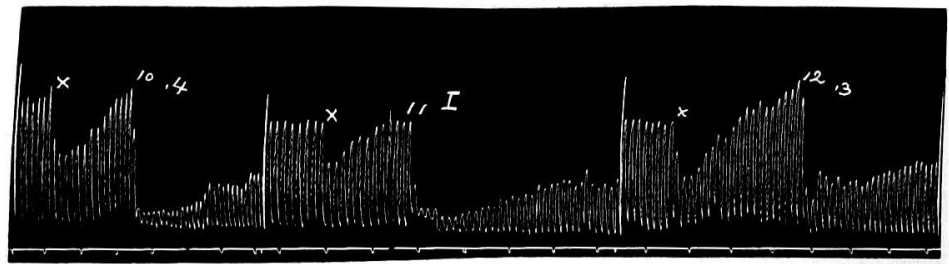

Fig. 4. a.§ At 10 and 12 adrenaline blood solutions which contained 0.4 c.c and 0.3 c.c. of adrenaline hydrochloride solution of $1: 200,000$ were respectively applied. At 11 I c.p. specimen solution was applied.

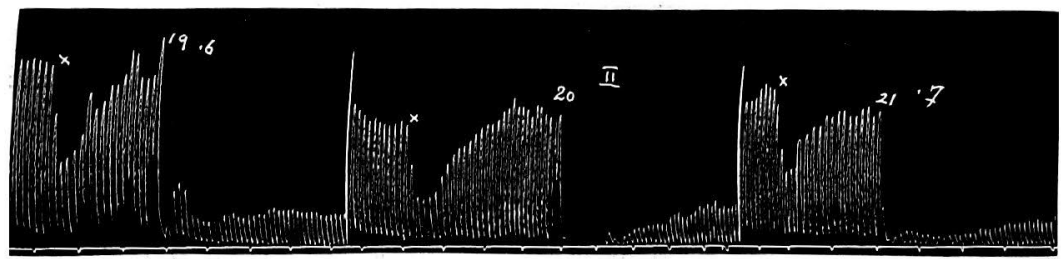

Fig. 4. b. At 19 and 21 adrenaline blood solutions which contained 0.6 c.c. and 0.7 c.c. of adrenaline hydrochloride solution of $1: 200,000$ were respectively applied. At 20 II. c.p. spec. solution was applied.

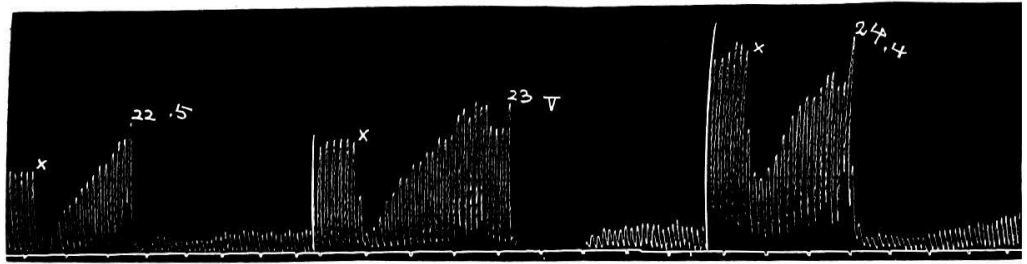

Fig. 4. c. At 22 and 24 adrenaline blood solutions which contained 0.5 c.c. and 0.4 c.c. of adrenaline hydrochloride solution of $1: 200,000$ were respectively applied. At $23 \mathrm{~V}$ c.p. spec. solution was applied.

$\S$ See the foot note on p. 374. 


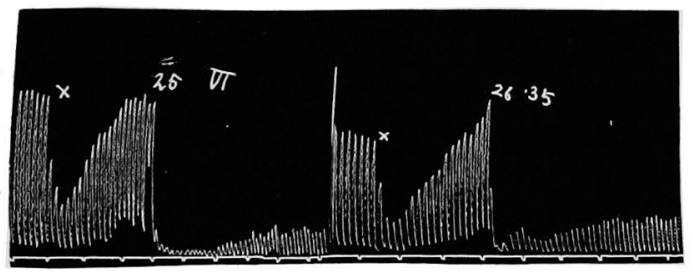

Fig. 4. d. At 25 VI c.p. spec. solution and at 26 adrenaline blood solution which contained 0.35 c.c. of adrenaline hydrochloride solution of $1: 200,000$ were applied.

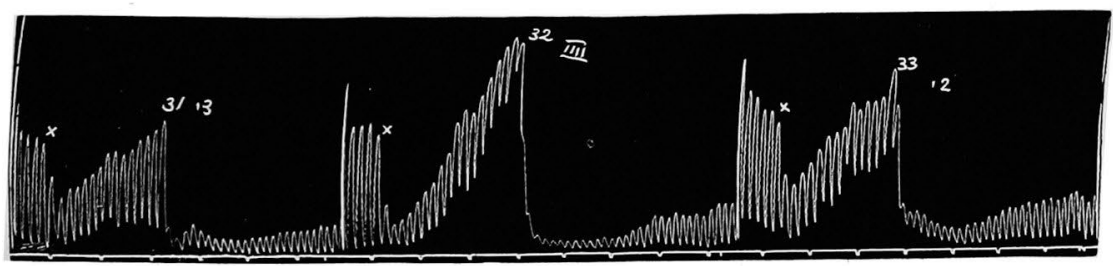

Fig. 4. e. At 31 and 33 adrenaline blood solutions which contained 0.3 c.c. and 0.2 c.c. of adrenaline hydrochloride solution of $1: 200,000$ were respectively applied. At 32 IV c.p. specimen solution was applied.

To sum up:

Sample I : Weaker than 0.4 c.c. of $1: 200,000$ per 0.5 c.c.; stronger than 0.3 c.c. of $1: 200,000$ per 0.5 c.c. I was taken as $0.0035 \mathrm{mgrm}$. in 1 c.c.

Sample II : Stronger than 0.6 c.c. of $1: 200,000$ per 0.5 c.c.; weaker than 0.7 c.c. of $1: 200,000$ per 0.5 c.c. II was taken as $0.0065 \mathrm{mgrm}$. in 1 c.c.

Sample IV: Stronger than 0.2 c.c. of $1: 200,000$ per 0.5 c.c.; weaker than 0.3 c.c. of $1: 200,000$ per 0.5 c.c. IV was taken as $0.0025 \mathrm{mgrm}$. in 1 c.c.

Sample V: Weaker than 0.5 c.c. of $1: 200,000$ per 0.5 c.c.; almost as strong as 0.4 c.c. of $1: 200,000$ per 0.5 c.c. $V$ was assayed at $0.004 \mathrm{mgrm}$. in 1 c.c.

Sample VI: Almost as strong as 0.4 c.c. of $1: 200,000$ per 0.5 c.c.; stronger than 0.3 c.c. of $1: 200,000$ per 0.5 c.c. VI was assayed at $0.004 \mathrm{mgrm}$. in 1 c.c.

These determinations were further verified by some other tracings not reproduced.

The ratio of the epinephrine content estimated by two methods :

\begin{tabular}{c|c|c|c}
\hline \multirow{2}{*}{$\begin{array}{c}\text { No. of } \\
\text { specimen }\end{array}$} & \multicolumn{2}{|c|}{ Epinephrine content in 1 c.c. (mgrm.) } & \multirow{2}{*}{$\begin{array}{c}\text { Ratio } \\
\text { Eye : Intestine }\end{array}$} \\
\cline { 2 - 3 } & by denervated eye & by intestine strip & \\
\hline I & 0.00225 & 0.0035 & $1: 1.5$ \\
II & 0.00325 & 0.0065 & $1: 2.0$ \\
IV & 0.00125 & 0.0025 & $1: 2.0$ \\
V & 0.002 & 0.004 & $1: 2.0$ \\
VI & 0.00175 & 0.004 & $1: 2.2$
\end{tabular}


TABLE

Parallel determinations of the epinephrine content paradoxical eye method and the

\begin{tabular}{|c|c|c|c|c|c|c|c|c|c|c|}
\hline \multirow{3}{*}{ 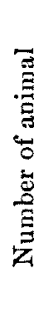 } & \multirow{3}{*}{ Date } & \multirow{3}{*}{ 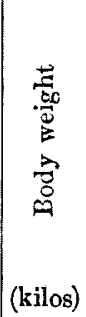 } & \multirow{3}{*}{ 成 } & \multirow{3}{*}{ 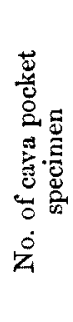 } & \multirow{3}{*}{ 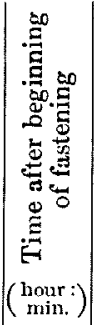 } & \multicolumn{4}{|c|}{ Blood flow (c.c.) } & \multirow{3}{*}{ 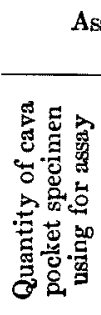 } \\
\hline & & & & & & \multirow[b]{2}{*}{ 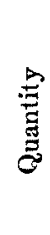 } & \multirow{2}{*}{ 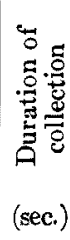 } & \multicolumn{2}{|c|}{$\begin{array}{l}\text { Quantity } \\
\text { per minute }\end{array}$} & \\
\hline & & & & & & & & 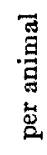 & 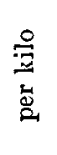 & \\
\hline
\end{tabular}

(a) So-called "spontaneous" out

\begin{tabular}{|c|c|c|c|}
\hline 26 & $\begin{array}{c}\text { 25. XII. } 1923 \\
\text { (Urethane) }\end{array}$ & .3 .6 & q \\
\hline 27 & 22. $\underset{(\text { Ether })}{1924}$ & 3.4 & $\hat{\delta}$ \\
\hline 28 & 24. $\underset{(\text { Ether })}{1924}$ & 3.0 & $\hat{0}$ \\
\hline
\end{tabular}

\begin{tabular}{l|r|r|r|r|r|r} 
I & 52 & 6.3 & 90 & 4.2 & 1.16 & 2.0 \\
II & $1: 06$ & 6.5 & 120 & 3.2 & 0.90 & 1.0 \\
III & $1: 28$ & 4.0 & 120 & 2.0 & 0.55 & 1.5 \\
& & & & & & \\
I & $1: 37$ & 3.2 & 90 & 2.1 & 0.61 & 0.5 \\
II & $1: 52$ & 3.0 & 120 & 1.5 & 0.44 & 0.5 \\
III & $2: 09$ & 3.2 & 180 & 1.1 & 0.32 & 0.5 \\
IV & $2: 26$ & 1.7 & 240 & 0.4 & 0.11 & 0.5 \\
& & & & & & \\
I & $1: 36$ & 3.1 & 120 & 1.5 & 0.5 & 1.0 \\
II & $1: 51$ & 3.3 & 150 & 1.3 & 0.43 & 1.0 \\
III & $2: 08$ & 3.9 & 180 & 1.3 & 0.43 & 1.0 \\
IV & $2: 26$ & 2.5 & 150 & 1.0 & 0.33 & 1.0
\end{tabular}

(b) Epineplinine output under light anaes

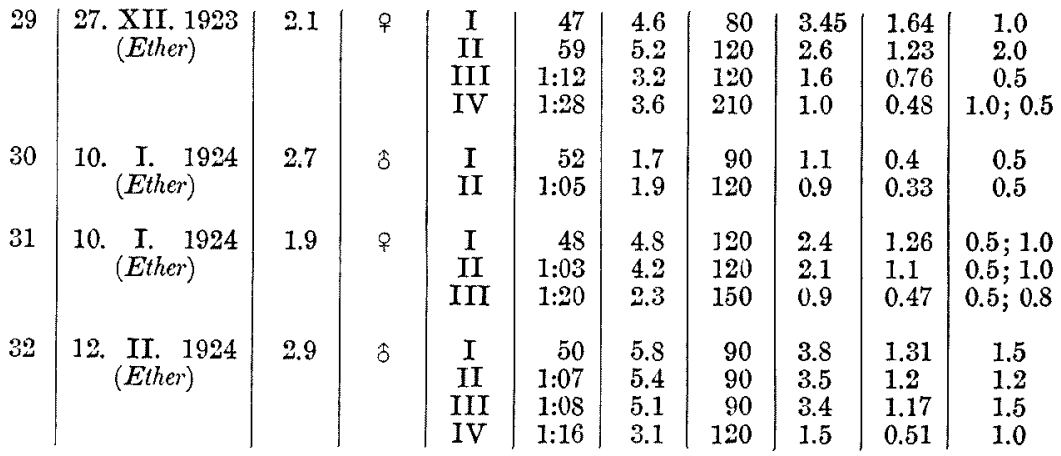

(c) Einephrine output by

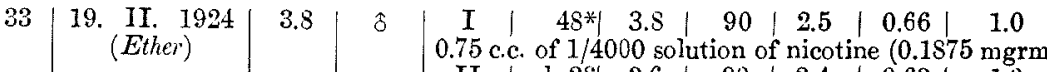

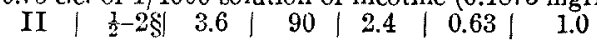

* Time before nicotine injection.

$\S$ Time after nicotine injection. 
II.

(and output) of the suprarenal rein blood by the rabbit intestine segment method.

\begin{tabular}{|c|c|c|c|c|c|c|c|}
\hline \multirow{2}{*}{\multicolumn{3}{|c|}{$\begin{array}{l}\text { ay by paradoxical eye } \\
\text { reaction of cat } \\
\text { Epinephrine output } \\
\text { (mgrm.) }\end{array}$}} & \multirow{2}{*}{\multicolumn{3}{|c|}{$\begin{array}{c}\begin{array}{c}\text { Assay by intestine strip } \\
\text { of rabbit }\end{array} \\
\frac{\begin{array}{c}\text { Epinephrine output } \\
\text { (mgrm.) }\end{array}}{}\end{array}$}} & \multirow{4}{*}{ 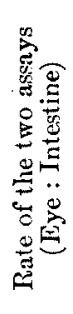 } & \multirow{4}{*}{ Remarks } \\
\hline & & & & & & & \\
\hline \multirow{2}{*}{ 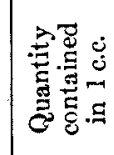 } & \multicolumn{2}{|c|}{$\begin{array}{c}\text { Output } \\
\text { per minute }\end{array}$} & \multirow{2}{*}{ 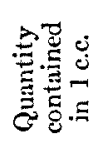 } & \multicolumn{2}{|c|}{$\begin{array}{c}\text { Output } \\
\text { per minute }\end{array}$} & & \\
\hline & $\begin{array}{l}\text { per } \\
\text { animal }\end{array}$ & $\begin{array}{l}\text { per } \\
\text { kilo }\end{array}$ & & $\begin{array}{c}\text { per } \\
\text { animal }\end{array}$ & $\begin{array}{l}\text { per } \\
\text { kilo }\end{array}$ & & \\
\hline
\end{tabular}

put of epinephirine from suprarenals.

\begin{tabular}{|c|c|c|c|c|c|c|c|}
\hline 0.00062 & 0.0026 & 0.00072 & 0.00085 & 0.00357 & 0.00099 & $1: 1.4$ & Denervated eye of Cat 36 . \\
\hline 0.0005 & 0.0016 & 0.00044 & 0.00087 & 0.00278 & 0.00077 & $1: 1.7$ & \\
\hline 0.00075 & 0.0015 & 0.00041 & 0.00125 & 0.0025 & 0.0007 & $1: 1.6$ & \\
\hline $0.0005-$ & - & - & 0.0006 & 0.00126 & $0.0008 \pi$ & $1: 1.2+$ & Denervated eye of Cat $3 \pi$ \\
\hline $0.0005-$ & - & - & 0.0008 & 0.0012 & 0.00035 & $1: 1.6+$ & \\
\hline 0.001 & 0.0011 & 0.00032 & 0.0014 & 0.00154 & 0.00045 & $1: 1.4$ & \\
\hline 0.002 & 0.0008 & 0.00023 & 0.0025 & 0.001 & 0.0003 & $1: 1.25$ & \\
\hline 0.0007 & 0.00105 & 0.00035 & 0.0015 & 0.00225 & 0.00075 & $1: 2.1$ & Denervated eye of $\mathrm{Cat} 3 \delta$. \\
\hline 0.00075 & 0.00097 & 0.00032 & 0.0014 & 0.00182 & 0.00061 & $1: 1.8$ & \\
\hline 0.00075 & 0.00097 & 0.00032 & 0.0015 & 0.00195 & 0.00065 & $1: 2.0$ & \\
\hline 0.00077 & 0.00077 & 0.00026 & 0.0018 & 0.0018 & 0.0006 & I : 2.3 & \\
\hline
\end{tabular}

thesia or without anaesthesia, and by massage.

\begin{tabular}{|c|c|c|c|c|c|c|c|}
\hline 0.00025 & 0.00086 & 0.00041 & 0.0005 & 0.00172 & 0.00082 & $1: 2.0$ & Denervated eye of Cat 30 . \\
\hline 0.00037 & 0.00096 & 0.00046 & & - & - & & \\
\hline 0.001 & 0.0016 & $(0.00076):$ & 0.00175 & 0.0025 & $(0.00133)$ & $1: 1.7$ & 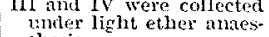 \\
\hline 0.0015 & 0.0015 & $(0.00071)$ & 0.00275 & 0.00275 & $(0.0013)$ & $1: 1.8$ & thesia \\
\hline 0.003 & 0.0083 & $(0.00122)$ & 0.006 & 0.0066 & $(0.00244)$ & $1: 2.0$ & \\
\hline 0.004 & 0.0036 & $(0.00133)$ & 0.008 & 0.0072 & $(0.00266)$ & $1: 2.0$ & $\begin{array}{l}\text { Specimens rere collected } \\
\text { without ether nurcosis. }\end{array}$ \\
\hline 0.00 & $0.002 t$ & $(0.00126)$ & 0.00175 & 0.0042 & $(0.00221)$ & $1: 1.7$ & Denervated eye of Cat 41. \\
\hline 0.0015 & 0.00315 & $(0.00165)$ & 0.00225 & 0.00478 & 0.00248 & $1: 1.5$ & \\
\hline 0.002 & 0.0018 & $(0.00094)$ & 0.003 & 0.0027 & $(0.00142)$ & $1: 1.5$ & $\begin{array}{l}\text { Specimens were collected } \\
\text { withont ether narcois. }\end{array}$ \\
\hline 0.0003 & 0.00114 & 0.00029 & 0.0004 & 0.00152 & 0.00052 & 1: & Denervated eye of Cat 4:. \\
\hline 0.00035 & 0.00122 & 0.00042 & 0.0007 & 0.00245 & 0.00084 & $1: 2.0$ & \\
\hline 0.0007 & 0.00238 & $(0.00082)$ & 0.0015 & 0.0051 & $(0.001$ & & Massage. \\
\hline 0.0009 & 0.00135 & 0.00046 & 0.002 & 0.003 & $(0.00103)]$ & $1: 2.2$ & $"$ \\
\hline
\end{tabular}

nicotine administration.

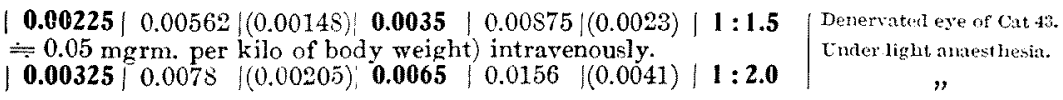

* The numerals in brackets show the output per kilo and per minute in the cases, when a special manipulation as massage, nicotine injection was undertaken. 


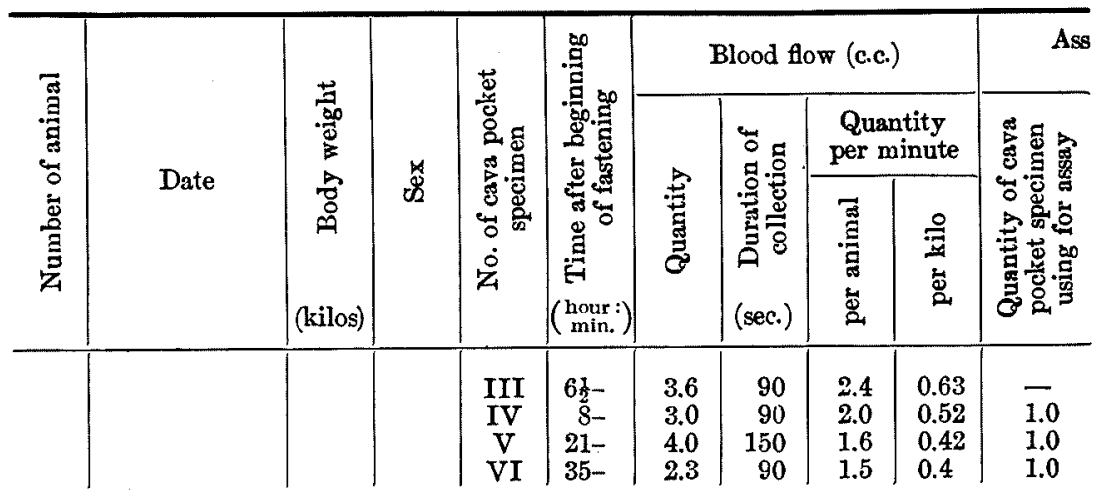

(d) Experiments in which bilaterally

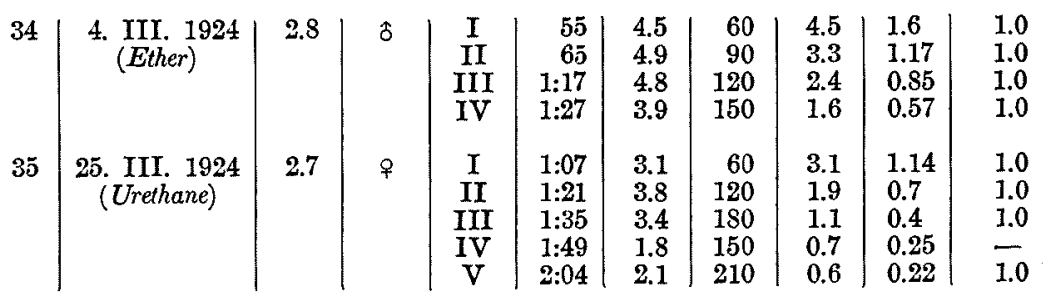

In Example VII the splanchnic nerves were previously divided, while they remained intact in Example VI. In Example VIII nicotine was administered.

In Example VI the cava pocket blood samples were collected from Cat 28 under ether anaesthesia. Cat 38, the left superior cervical ganglion of which was removed 8 days before, was employed for the paradoxicaloreaction. The pupil width, which was $5.0 \mathrm{mms}$. immediately after fastening, increased to $6.0 \mathrm{mms}$. in about twenty minutes, but it decreased later so that it was measured as $3.0 \mathrm{mms}$ in two hours. We often came across such a tendency towards the repeated injections of adrenaline fluids in the cats without being provided with the cava pocket.

The cava pocket specimens, diluted with two volumes Tyrode for one volume specimen, were injected into the right external jugular vein in a desired quantity of 1.0 c.c. The adrenaline blood solutions for comparison were prepared by taking: Indifferent blood from Cat 28 1.0, Tyrode 2.0$2 \alpha$, double Tyrode $\alpha$ and adrenaline hydrochloride solution, diluted with distilled water, $\alpha$.

As may be readily seen from examination of the protocol the amount of dilation occasioned by 1 c.c. of the $I$ cava pocket specimen was just the 


\begin{tabular}{|c|c|c|c|c|c|c|c|}
\hline \multirow{2}{*}{\multicolumn{3}{|c|}{$\begin{array}{l}\text { ay by paradoxical eye } \\
\text { reaction of cats } \\
\begin{array}{c}\text { Epinephrine output } \\
\text { (mgrm.) }\end{array}\end{array}$}} & \multirow{2}{*}{\multicolumn{3}{|c|}{$\frac{\begin{array}{c}\text { Assay by intestine strip } \\
\text { of rabbit }\end{array}}{\text { Epinephrine output }}$}} & \multirow{4}{*}{ 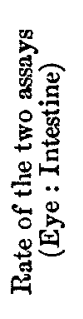 } & \multirow{4}{*}{ Remarks } \\
\hline & & & & & & & \\
\hline \multirow{2}{*}{ 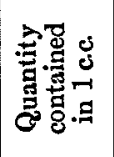 } & \multicolumn{2}{|c|}{$\begin{array}{c}\text { Output } \\
\text { per minute }\end{array}$} & \multirow{2}{*}{ ن } & \multicolumn{2}{|c|}{$\begin{array}{l}\text { Output } \\
\text { per minute }\end{array}$} & & \\
\hline & $\underset{\text { animal }}{\text { per }}$ & $\begin{array}{c}\text { per } \\
\text { kilo }\end{array}$ & & $\underset{\text { animal }}{\text { per }}$ & $\begin{array}{l}\text { per } \\
\text { kilo }\end{array}$ & & \\
\hline $\begin{array}{l}0 . \overline{00125} \\
0.002 \\
0.06175\end{array}$ & $\begin{array}{l}-\overline{0.0025} \\
0.0032 \\
0.00262\end{array}$ & $\begin{array}{c}-\overline{0} \\
(0.00065) \\
(0.00084) \\
(0.00069)\end{array}$ & $\begin{array}{l}0 . \overline{0025} \\
0.004 \\
0.004\end{array}$ & $\begin{array}{l}0 . \overline{005} \\
0.0064 \\
0.006\end{array}$ & $\left(\begin{array}{c}(0.00131) \\
(0.00168) \\
0.00157)\end{array}\right.$ & $\begin{array}{l}1: 2.0 \\
1: 2.0 \\
1: 2.2\end{array}$ & $\begin{array}{c}\text { Under light anaesthesia. } \\
\text { " } \\
"\end{array}$ \\
\hline
\end{tabular}

splanchnectomized cat's eye was employed.

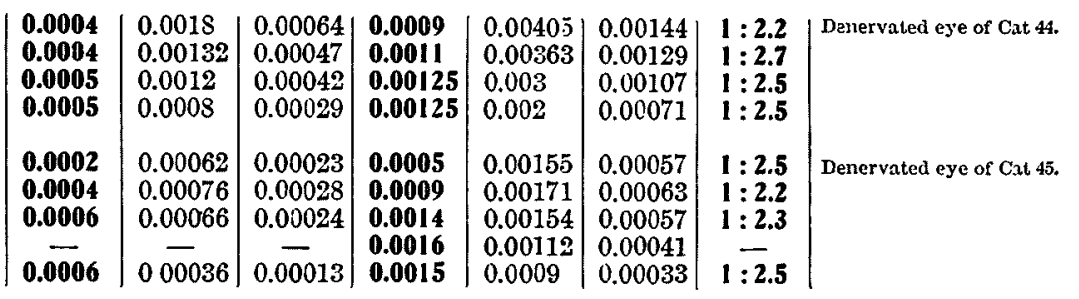

same as that induced by 0.7 c.c. of $1 / 1000 \mathrm{mgrm}$. adrenaline in 1 c.c., those by II and III c.p. specimens were found to be just midway between those by 0.7 c.c. of $1 / 1000 \mathrm{mgrm}$. in 1 c.c. and 0.8 c.c. of the solution of the same strength, and IV c.p. specimen was only a little weaker than 0.8 c.c. of $1 / 1000$ mgrm. in 1 c.c., as the whole.

So the epinephrine content in 1 c.c. of I. c.p. specimen was taken as 0.0007 mgrm., that in II and III as 0.00075 mgrm., and IV as 0.00077 mgrm. From these values and the blood flow velocity from the cava pocket, the rate of epinephrine output was calculated as shown in the Example. The pocket blood samples were also determined by the rabbit intestine strip method.

Comparing the epinephrine output for each set of experiments or the epinephrine content obtained by both methods, the results are:

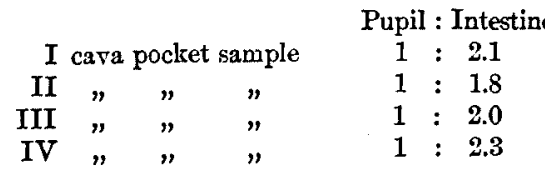

In Example VII the cava pocket specimens were collected from Cat 35 under urethane narcosis. Cat 45 was previously doubly splanch- 
nectomized, thereafter the left superior cervical ganglion was removed 8 days prior to the determinations. In general the denervated pupil in the doubly splanchnectomized cat is very narrow and fairly unaltered for a long period of time, so that determinations can be quite easily carried out on this pupil. The sensibility of the denervated pupil is, too, raised by the doubly splanchnectomy. In Cat 45 of Example VII the lowest limit for causing the dilation was $0.000034 \mathrm{mgrm}$. per kilo of body weight, while in Cat 38 of Example VI, in which the splanchnic nerves were not interfered with, it was 0.0002 mgrm. per kilo.

The ratios of values obtained by both methods are :

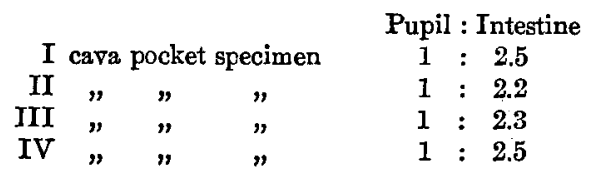

In Example VIII the cava pocket bloods were taken from Cat 33 under ether, and nicotine was intravenously injected in a dose of about 0.05 mgrm. per kilo. The pocket samples were collected repeatedly. The time variation of the epinephrine output coincided with the data given in the previous communication. ${ }^{17}$ The ratio of the values of output or concentration was (Pupil : Intestine) $1: 1.5$ (before nicotine), $1: 2.0,1: 2.0$, $1: 2.0$ and $1: 2.2$.

Turning now to Table II, in observations of 7 cats the so-called spontaneous liberation determined by the paradoxical eye reaction was $0.00013-$ $0.00072 \mathrm{mgrm}$. per minute and per kilo, the average being $0.00036 \mathrm{mgrm}$., and that by the rabbit intestine $0.0003-0.00144$ mgrm., mean 0.00075 . The ratio of the two assays (Pupil : Intestine) was $1: 1.2-1: 2.7$, mean 1 : 2.0 .

Further, the ratio gained with the samples collected under light anaesthesia, without anaesthesia, by massage or under the influence of nicotine, ranged as $1: 1.5-1: 2.6$.

Taking 34 observations of 10 cats altogether the ratio (Pupil : Intestine) was $1: 1.2-1: 2.7$, on an average $1: 1.9$.

This ratio (Pupil : Intestine) $1: 1.9$ coincides strikingly with the ratio observed in the foregoing chapter, that is, the ratio of the auto-pupilassay to the external-rabbit-intestinal-assay, 1:1.7. By this close agreement of the ratios detected in both sets of experiments we are justified in 
assuming that the difference obtained by the auto-pupil-assay and the external-rabbit-intestine-assay is nothing other than that inherent to the pupil and the rabbit intestine segment methods themselves, and whether the blood is estimated in the body in situ or outside of the body has no material influence upon this difference. And further it must be granted that the dissimilar experimental conditions in flowing of epinephrine or adrenaline in the general circulation between releasing the upper path of pocket and the injections of adrenaline solutions for comparison as practized in the present investigations, etc. exert no appreciable bearing upon this difference.

On the fact that the suprarenal vein blood exerts different degree of influence according to the organe affected, as the denervated pupil of cat and the rabbit intestine segment, the action of adrenaline hydrochloride being taken as the standard, we are not able to find previous references, and this fact seems strange to us. But we have come to find some analogies in the extracts of the suprarenal gland or its medulla of the ox, pig, dog and cat. Experiments on the extracts have been and are being carried out in a vast scale in our Laboratory. By the data on the extracts acquired we are confirmed in coming to the above expressed conclusion.

The pupil was neither deprived of the ciliary ganglion nor atropinized while the intestine strip was usually atropinized in our Laboratory. In order to seek for any influence of excluding the parasympathetic nerve, some additional experiments were undertaken. Namely the intestine segment was not atropinized to begin with and some cava pocket samples as well as medullary extracts were estimated therewith for epinephrine content against the adrenaline solutions of known strength, then atropine came into application to the segment and the estimations with the same specimens were repeated, quite the same values in both the sets being yielded. Therefore, the exclusion of the parasympathetic influence had no least relation to the difference in values obtained by these different methods.

IV.

\section{SUMMARY.}

(1) Techniques in utilizing the cat with the denervated pupil (only the superior cervical ganglion was removed) for estimation of epinephrine content of bloods or extracts are fully illustrated in the text.

(2) The rate of epinephrine output in cats was estimated by the autopupil-assay, and by the rabbit segment method, the bloods from the cava pocket being collected outside of the body. Adrenaline hydrochloride was taken as the standard. The values obtained by the two methods did not ever coincide with each other. The values achieved by the auto-pupilassay were invariably inferior to those by the external-rabbit-intestine- 
segment method, the ratio being $1: 1.2-1: 2.8$, or $1: 1.5-1: 2$ in most cases, and mean 1 : 1.7 .

These values agree with those recently reported by Stew art and $R$ og off, but they came to a different conclusion than the present writer, some earlier data indicating a quite reverse tendency being taken for averaging.

(3) The bloods from the cava pocket of cats were estimated for epinephrine content against the adrenaline hydrochloride solutions of known strengths firstly by the paradoxical pupil reaction of another cat, the splanchnic nerves of which were either interfered with or remained intact, and secondly by the rabbit intestine strip method. The results were quite similar to those summarized above (2). The intestine strip method invariably yielded more or less higher values than the pupil method, and the ratio (Pupil : Intestine) did not materially differ from that between the auto-pupil-assay and the external-rabbit-intestine segment-assay, that is the ratio was this time $1.2: 1-1: 2.7$, on an average $1: 1.9$.

By the results in this set of experiments is borne out the conclusion that the suprarenal vein blood of cats exerts a more powerful action upon the rabbit intestine than upon the denervated pupil of the cat, adrenaline hydrochloride being taken as the standard.

The above mentioned apparent divergency in the rates of epinephrine output according to the methods employed, that is the auto-pupil-assay and the external-rabbit-intestine-segment method, can be fairly explained by the reason of this property of the suprarenal vein blood. 